\title{
El Hospital Central de la Defensa Gómez Ulla, entre la nostalgia y la esperanza al contemplar los 125 años de su historia
}

\author{
Herrera-de-la-Rosa A. ${ }^{1}$
}

Sanid. mil. 2021; 77 (1): 47-62, ISSN: 1887-8571

Era el mes de julio de 1963, estaba yo en Madrid, recién licenciado en Medicina, y antes de regresar a Melilla, lugar donde había nacido 24 años antes, me fui a ver el Hospital Militar Gómez Ulla.

La enorme puerta de la entrada conducía a un zaguán, donde la continua brisa se agradecía en el verano madrileño. Al zaguán se le abrían puertas y escaleras a ambos lados y era, a la vez, túnel de paso al hospital propiamente dicho. Al entrar no tuve que enseñar documentación alguna, aunque yo, en previsión, llevaba mi carnet de alférez de complemento, documento bien ganado en los dos veranos de mi Servicio Militar.

Una vez dentro rodeé el primer pabellón que lucía una galería acristalada y me encontré con la disposición de la obra. No se parecía ésta al Hospital Clínico, inacabado, de la Ciudad Universitaria, que aunque era, en gran parte, esqueleto arquitectónico, reliquia de batallas de la Guerra Civil, se presentaba como una mole de hormigón y ladrillo, con la breve habilitación de su esquina sur para cursar allí la Patología General. Tampoco era el Gómez Ulla como el otro Hospital de mi vida de estudiante, el Provincial, unido a la Facultad de San Carlos de la calle Atocha, donde se prolongó mi carrera de siete años. También se diferenciaba de la enorme estructura que se estaba construyendo en La Castellana, cuyo nombre quería recordarnos que se inauguraría al año siguiente para conmemorar aquellos 25 años de Paz, que eran los que marcaban los años de mi existencia.

No, el Gómez Ulla no era nada parecido a estas estructuras verticales, más o menos modernas, pero a mí no me extrañó. Yo había nacido y vivido en Melilla, ciudad española, cercada por el mar y la frontera, donde la Fuerzas Armadas tenían, durante toda su historia, especial protagonismo. En Melilla, el hospital más emblemático de la ciudad era el Hospital Pagés, construido en 1910 con barracones de madera, tipo Dóker, dada la apremiante necesidad que las campañas del Norte de África, tenían de un hospital.

A ese Hospital, los melillenses, lo llamábamos, indistintamente, «El Pagés» o «El Dóker» sin que casi nadie se preguntara qué significaban aquellos nombres, ni siquiera las mujeres, que parían aliviadas con la anestesia epidural, sabían que Fidel Pagés con su «anestesia metamérica» era el responsable de tan feliz hallazgo. Pero ese nombre no era ajeno a los médicos mili-

${ }^{1}$ Coronel Médico Retirado. Exdirector Ejecutivo de la Revista de Sanidad Militar.

Recibido: 10 de marzo de 2021

Aceptado: 18 de marzo de 2021

doi: $10.4321 /$ S1887-85712021000100009 tares que tenían en el quirófano la lápida que recordaba: «Aquí operó Pagés; sirviendo a la patria, enalteció a la ciencia». Ese Hospital, tipo Dóker, lo conocí yo en mi infancia y juventud, convertidos ya los barracones en firmes edificios de mampostería, por eso la visión del Gómez Ulla, con su distribución en edificios bajos, ordenados con cierta armonía, propia del estilo Tollet, me resultaba familiar, me enlazaba con mi pueblo, me llevaba a casa y dirigía mi vocación.

Mi idea estaba trazada. En la primavera del año siguiente ingresé en Sanidad Militar. Pasé fugazmente por las salas del Gómez Ulla para examinarme del ejercicio práctico de la oposición y le eché un guiño al Hospital: «Espérame, pienso volver».

Mis siete años de África me llevaron por el Sahara, Melilla y el Peñón de Alhucemas a gustar y sufrir por los escenarios donde se ubica «la gran familia militar». En 1972 volví al Gómez Ulla, a cursar mi especialidad de Pulmón y Corazón y allí mi vida se uniría al Hospital para seguir cumpliendo años durante mucho tiempo.

De nuevo, después de diez años, volví a contemplar el Hospital Militar de Carabanchel, que se me presentaba ahora como un recinto amurallado, donde se alzaba una iglesia de estilo ojival o neogótico, que quería ser el centro geométrico de un conjunto arquitectónico, que mostraba ya los estragos de su decadencia. Ni los recintos ajardinados, ni las calles sombreadas, ni los edificios de ladrillos rojos mostraban la solidez y armonía del conjunto, Además era evidente el deterioro de las instalaciones y los «parches» que había ido exigiendo el paso del tiempo.

Cuando escribo esto han pasado casi 50 años, estoy en situación de retirado, adscrito a la Inspección General de Sanidad y pertenezco al Comité de Redacción de esta Revista, y su Director Ejecutivo actual, José Ignacio Robles ${ }^{(1)}$, me pide un artículo sobre los 125 años que cumple este Hospital en los mismos días en los que el BOD publica la siguiente Orden Ministerial: El Hospital Central de la Defensa Gómez Ulla pasará a denominarse: «Hospital Central de la Defensa Gómez Ulla, Centro Sanitario de Vida y Esperanza», acertada decisión de la Ministra Margarita Robles, que ha inspirado el título de este artículo, porque el horizonte de Esperanza

(1) José Ignacio Robles fue jefe de Psicología Clínica del HCDGU y Jefe de la Subunidad de Docencia e Investigación de la Inspección General de Sanidad. En la actualidad sigue adscrito a esta Inspección disfrutando de un merecido y fructífero retiro como Profesor. Con gran amabilidad y su natural paciencia de buen psicólogo, me ha ayudado con fechas y acontecimientos y me ha facilitado la documentación de la Revista, que dirige, para la realización de este artículo. 
no quita, sino que invita, a la nostalgia para contemplar esos 125 años de su historia, adentrarse necesariamente en sus raíces y recordar que todo empezó el 8 de febrero de 1889 con el incendio del Seminario de Nobles de la calle de La Princesa, que se había convertido en Hospital Militar.

El Seminario de Nobles ${ }^{(2)}$ era un recio edificio de tres plantas que había fundado Felipe V para la educación de los hijos de la nobleza, a imitación de los que tenían los jesuitas en Viena. El edificio se terminó de construir en 1751, reinando Fernando VI. En 1783 y tras la expulsión de los jesuitas en tiempos de Carlos III, se convirtió en un centro de enseñanza para hijos de militares y, dado su enorme tamaño, empezó a usarse para la ubicación de determinadas unidades de tropas. En 1828 Fernando VII lo restituye a los jesuitas, que recuperan la enseñanza para algunos hijos de la nobleza, hasta que en 1835 la Reina Regente, doña María Cristina de Borbón expulsa de España a la Compañía de Jesús. En ese tiempo se cierra la Universidad de Alcalá y el antiguo Seminario de Nobles se considera idóneo para albergar a la recién creada, en 1836, Universidad Central, la cual, en 1840, cambia su asentamiento y la Facultad de Medicina se instala en el Real Colegio de Cirugía de San Carlos. Del edificio, que ya tiene más de un siglo y está en lamentable estado, se hace cargo el Ministerio de la Guerra, que, tras su reparación, recibirá, en 1841, a los enfermos, que tras otras vicisitudes, estaban en el Hospital del Convento de Atocha y en la llamada Enfermería de la Cárcel del Saladero. Desde entonces el antiguo Hospital de Nobles empezó a funcionar como el Primer Hospital Militar de Madrid, que fue destruido por el incendio citado, lo que obligó a pensar en un nuevo Hospital Militar para Madrid.

El Ayuntamiento de Carabanchel Bajo aprovechó el incendio del Seminario de Nobles para ofrecer unos terrenos en los que se construiría el nuevo Hospital.

El proyecto que se aprobó para esta construcción fue el que presentó el Capitán de Ingenieros D. Manuel Cano y León el 30 de septiembre de 1889. En él se especifican ideas de tipo general y la mayoría de los detalles que se llevarían a cabo. Se utilizaría el Sistema Tollet, similar al de los Hospitales de La Santa Cruz y San Pablo de Barcelona y el de la Fundación Marqués de Valdecilla de Santander.

Se tuvieron en cuenta los dos niveles del terreno para separar los edificios de enfermos comunes de los destinados a enfermos contagiosos. En la parte más baja se colocaría la puerta principal que formaba parte del edificio de Dirección y Administración y tendría forma de U. Inmediatamente detrás, dejando una espaciosa calle, se colocaría el pabellón destinado a jefes y oficiales enfermos, y detrás de éste, la gran plaza central con la capilla. A ambos lados de la plaza iban los seis pabellones de medicina y cirugía, de éstos, dos estarían dedicados a salas de cirugía. Se diseñó allí, como un anexo, el pabellón de operaciones, unido a ellos por una galería acristalada. Detrás iban los pabellones destinados a dementes, presos y sumariados y completaban este espacio el cuartel de sanitarios y las cocheras.

\footnotetext{
(2) Este edificio forma parte de la «Prehistoria» del Hospital, como dice mi amigo José Miguel Torres Medina, Coordinador y Director del Libro del Centenario, del que cojo gran parte de los datos de este artículo.
}

Como se había pensado, el plano de nivel superior, separado por una escalera y dos rampas, se destinaba a los pabellones de enfermedades infecciosas y al depósito de cadáveres. Próximo a las rampas referidas se instalarían los depósitos de agua.

Todo el edificio se presentaba rodeado de un muro de cerca. Para el acceso al interior del establecimiento, además de la puerta principal, que formaba parte del edificio de la Dirección, habría otras dos puertas de un bello enrejado de hierro, cuyo diseño figuraba en los planos, por donde entrarían los carruajes y el tranvía ${ }^{(3)}$.A continuación del Pabellón de Dirección estaba previsto hacer un pabellón destinado al Instituto Anatomopatológico, que nunca llegó a construirse. Este Instituto, que con otros nombres y anexionando cometidos llegaría a ser el Instituto de Medicina Preventiva de la Defensa, tardaría más de cien años en incorporarse a este Hospital ${ }^{(4)}$.

Respecto a la iluminación, que en esa época era un lujo sólo para privilegiados, apunto un dato para situarnos en la historia. Cano y León, al tratar de la electricidad concluye: «...el alumbrado eléctrico, caso de establecerse, se deberá instalar una vez terminadas las obras ...»

La construcción del Hospital Militar en Carabanchel tenía también el problema de su distancia, estaba a cinco kilómetros de la Puerta del Sol, pero se tenía la idea de unirlo con dos medios de transporte, el ferrocarril que uniría Madrid a San

(3) Las vías del tranvía que entraba en el recinto del Hospital, las seguí viendo yo durante años semienterradas en el asfalto de la Glorieta del Ejército y en varias calles interiores del Hospital.

(4) A ese Pabellón, que nunca se construyó, iban a trasladarse dos servicios o instituciones que se encontraban en un Torreón del Seminario de Nobles. Uno era el Museo Anatómico, que era preceptivo tenerlo con fines didácticos. Había sido creado por una R.O. de 1886. Este Museo no corresponde a la idea actual de museo y estaba dirigido por el Médico Primero D. Juan Cesáreo Fernández y Fernández Losada, que llegó a ser Inspector del Cuerpo. En el Museo había unas piezas anatómicas confeccionadas en cera por el escultor y pintor Enrique Zofio Dávila y otras piezas fabricadas con una técnica de pasta de cerámica original de Fernández y Fernández Losada.

El otro servicio era el Instituto Anatomopatológico, que tras diversos nombres y absorciones, que luego apuntaré, se convirtió en Instituto de Medicina Preventiva. Tomó su propio rumbo bajo la Dirección de Fernández Losada. Instalándose primero en un chalet de Rosales y otras ubicaciones, lo vimos, en época reciente, en el mismo edificio, que el Hospital del Generalísimo, en la calle Isaac Peral.

El hospital que se estaba construyendo tendría, sin duda su propio laboratorio, pero ya no era el Instituto previsto con animalario para análisis e investigación.

Lo que se salvó del Museo Anatómico tras el incendio sí se trasladó a otra dependencia del Hospital Militar y allí fue su Director el Médico Mayor D. Eduardo Semprún y Semprún, que había estado en La Habana desde 1889, y después fue comisionado a Francia, Inglaterra, Suiza y Alemania con objeto de adquirir lo necesario para el montaje del método de Radiografía, descubierto por Konrad Roentgen en 1895.

El Doctor Semprún, un hombre polifacético, fue el Director del Gabinete de Radiología cuando se instaló definitivamente en el Hospital Militar de Carabanchel, pero además era un hábil fotógrafo de preparaciones microscópicas y realizó un álbum de microfotografías histológicas y bacteriológicas, algunas coloreadas posteriormente, al que puso el curioso nombre de Museo Anatomopatológico, pero que nada tiene que ver con el Museo Anatómico citado, el cual, tras su paso por el Hospital y al final por la Academia de Sanidad Militar desapareció por completo. El Museo actual de Sanidad Militar, que ocupa el Pabellón conservado del viejo Hospital de Carabanchel, que sí cumple con la idea actual de Museo, inauguró su actual trayectoria, como ya indicaré, en 1996 con motivo del Centenario. 


\section{El Hospital Central de la Defensa Gómez Ulla, entre la nostalgia y la esperanza...}

Martín de Valdeiglesias y un tranvía eléctrico (no de mulas) del que ya he hablado, que llegó el mes de agosto de 1898.

En 1895 estalló la revolución en Cuba, como consecuencia de estos hechos, el Ejército Español, junto a páginas de gloria, sufrió muchas pérdidas humanas, los Hospitales de Cuba y Filipinas se llenaron de soldados afectados más por enfermedad que por heridas de guerra. Sólo en Cuba hubo 58.000 fallecidos por enfermedad y 16.000 fueron evacuados, como inválidos totales. Por todo ello se comprende la necesidad de acelerar las obras del Hospital Militar de Carabanchel.

En 1896 llegaban los primeros pacientes de ultramar, muchos de ellos enfermos de paludismo, fiebre amarilla, disentería. El Hospital ya podía recibir enfermos, pero no se terminó hasta 1903.

1898 fue el año del desastre que marcó una generación. Fue enorme la repatriación de enfermos en buques hospitales, que fueron recibidos, no sólo en el Hospital Militar de Carabanchel, sino en los Hospitales Militares de Valladolid, Burgos, Vitoria, Bilbao, Pamplona etc.

Se debe citar que en este principio del siglo XX, se fueron creando unos cursos que constituyeron el inicio de las Especialidades Médicas, de cuya formación Sanidad Militar fue pionera en España. Su antecedente fueron las Comisiones de Estudio en el Extranjero, principalmente, el Instituto Pasteur. Las plazas para conseguir estos cursos se otorgaban por concurso oposición que incluía el conocimiento del idioma. Posteriormente se establecieron cursos, dirigidos por Médicos Militares en el Instituto de Higiene Militar (Heredero del Instituto Anatomopatológico, antes citado) situado en Rosales 12, y en el Hospital Militar de Carabanchel, que trataban de Micrografía, Urología, Radiología, Análisis Clínicos... ${ }^{(5)}$.

Cuando, en 1903, se terminaron las obras del Hospital Militar de Madrid-Carabanchel, que el año anterior se llamó por primera vez Central, tuvo lugar el XIV Congreso Internacional de Medicina, que universalizó al Hospital Militar. Este Congreso fue inaugurado por el Rey Alfonso XIII acompañado de su Augusta Madre. Este Congreso dividido en 16 secciones, la número 14 estuvo dedicada a Medicina e Higiene Militar y Naval, por lo que los congresistas, inscritos en esta sección, tuvieron la oportunidad de visitar el Hospital Militar de Carabanchel.

Aunque el Rey ya había visitado el hospital en 1902, fecha de su mayoría de edad, con motivo de la explosión de los polvorines del Campamento de Carabanchel, no fue hasta el 8 de enero de 1907 cuando tuvo lugar la visita oficial de sus Majestades los Reyes Alfonso XIII y Victoria Eugenia, cuya boda se había celebrado el año anterior. Tres años más tarde, en 1910,los Reyes volvieron al Hospital para inaugurar una escultura mural en memoria de los Médicos Militares muertos

\footnotetext{
(5) En diversos momentos de esta historia me referiré al hecho de ser la Sanidad Militar la pionera de establecer una Formación Posgrado y ser especialmente hospitalaria. Pero la filosofía de este hecho, queda claro desde su inicio. No se trata de buscar «Médicos elitistas» en la Profesión Médica Militar sino como dice la R.O., que convocó los cursos en el extranjero se trataba de ...proporcionar al Ejército de todos los recursos que la ciencia posea para la profilaxis y el tratamiento de las enfermedades. Las Especialidades Médicas surgen por el progreso de la Medicina y su especialización constituye una necesidad.
}

en acción de guerra, cumpliendo con su humanitaria acción, donada por suscripción de médicos militares. Esta lápida conmemorativa la realizó el notable escultor académico de Bellas Artes D. Eduardo Barrón y en ella quedaron recogidos de forma sucinta sus nombres y el año de su muerte ${ }^{(6)}$.

Esta lápida, que se conservó en el Pabellón de Dirección, tiene un ángel en la parte superior, que la abraza, y en la inferior lleva la Cruz de Malta rematada con la Corona Real bajo la cual se cruzan un sable y el caduceo de Esculapio con la serpiente enroscada.

El paso del siglo XIX al siglo XX obliga a aceptar que el edificio no sólo es otro, sino que es otra cosa. El siglo XIX, con las limitaciones de su época, ha quedado atrás, ahora la novedad no sólo se presenta con otro edificio, sino que exige otra forma de trabajo. Pero el cambio de siglo no es algo inmediato sino progresivo, y es difícil, para la visión global de la historia, marcar demasiado los años, pero si se quiere dar una fecha de inicio, hay que hacerlo, como dice Laín, considerando que el siglo XX no empieza realmente hasta la Gran Guerra. Por eso al narrar un tiempo que empieza tras este enfrentamiento bélico, me referiré ahora a la época, que en el mencionado libro del Centenario, comenta mi otro amigo y mentor Agustín Esteban, que abarca las dos guerras mundiales, la de Marruecos y la Guerra Civil Española, y como él dice, se caracteriza por los grandes cirujanos ${ }^{(7)}$.Pero antes citaré de nuevo las Especialidades Médicas.

En 1914 había surgido el Ateneo de Sanidad Militar, que fue un nuevo empuje a las Especialidades Médicas que la modernidad sigue imponiendo. En estos años se crearon cursos de Cirugía en 1916 y de Oftalmología en 1918 que abarcaban la duración de todo un año académico.

Los Cursos para la formación en Especialidades Médicas en el Hospital de Carabanchel siguieron convocándose en los años sucesivos. En 1931 la Formación de Especialistas en Fimatólogía, que luego se llamó de Tisiólogía, estuvo a cargo del Dr. Valdés Lambea. En 1932 se realizaron los cursos para la formación de las siguientes especialidades: Cirugía Ortopédica y Reeducación de Inválidos, Higiene y Bacteriología, Radiología, Otorrinolaringología, Oftalmología, Urología, Tisiología, Psiquiatría, Dermatología y Sifilografía. Esta convocatoria fue la última de esta etapa. Durante la República y la Guerra Civil no hubo cursos de especialidades.

\footnotetext{
(6) Debo anticipar aquí que en los primeros años del siglo XXI, el historiador Alejandro Belaústegui, sobrino de Eduardo Barrón, que estaba escribiendo sobre las obras de su tío, envió a la Revista de Sanidad Militar un artículo sobre esta placa y se interesó por las acciones de los Sanitarios Militares que en ella aparecían, por lo que inició una serie de artículos sobre sus biografías que dio lugar a una colección de diez tomos sobre Sanitarios Militares ejemplares, titulada la lucha contra el olvido.

(7) Esteban se refiere a Gómez Ulla, Bastos Ansart y Gómez Durán, que marcaron una época en este Hospital. Estimo que no quiere decir que luego no hubiera grandes cirujanos, que los hubo, sino que luego se cuenta más la cirugía por adelantos de las técnicas y sus posibilidades quirúrgicas. Además, a la escuela del último de ellos, pertenece el mismo Agustín Esteban, que dedicó su vida profesional a la Cirugía, especialmente a la Cirugía Torácica, de la que fue fundador en el Nuevo Hospital, y después, ya retirado, a una fructífera actividad en Humanidades Médicas.
} 
Pero fue la Cirugía la que cobró especial significación por la presencia de eminentes cirujanos: Pagés, Gómez Ulla, Bastos Ansart y Gómez Durán, de los que será preciso apuntar algunos datos, recogidos de los apuntes biográficos que aporta el Doctor Esteban en el Libro del Centenario.

En el Hospital, que ya tiene 20 años, se hacen reformas, pero no es sólo por su edad, es que la Ciencia, y especialmente la Medicina van deprisa, y de forma especial la que atañe a la Sanidad Militar. Europa se ha enfrentado a una Guerra de gran dureza y, como ocurre siempre a la sombra de los conflictos bélicos, surgen los descubrimientos y se perfeccionan las técnicas.

España tras esa Guerra, en la que ha sido neutral, se encuentra con su particular Campaña en el Norte de África y en ella será Fidel Pagés el que aporte su «Anestesia Metamérica» de la que ya he hablado. El Hospital Militar de Carabanchel tuvo papel en esta guerra no sólo contribuyendo con médicos expertos. El Hospital trató también las secuelas de las heridas y enfermedades que aquella campaña causó, como había hecho con los repatriados de ultramar cuando se inauguró 25 años antes.

Dejaré de momento a Fidel Pagés porque su temprana muerte, en un accidente de carretera, nos privó de su ingenio y habilidad quirúrgica demasiado pronto, y contaré la historia recogiendo de las vidas de los otros tres grandes cirujanos su relación directa o indirecta con el Hospital Militar de Carabanchel.

Mariano Gómez Ulla ingresó en Sanidad Militar en 1899. En 1909, tras leer su tesis doctoral sobre «La Desinfección en el Ejército», tuvo su primera experiencia africana en los sucesos del Barranco del Lobo. Con sus ambulancias desarrolló allí una notable labor y comenzaron a aflorar sus dotes de organizador nato.

Llegó por primera vez al Hospital en 1911. Se sintió siempre cirujano militar, y además de su maestría quirúrgica, aportó la Logística Sanitaria de los Hospitales Quirúrgicos de Campaña. Visitó en la Gran Guerra a ambos bandos beligerantes, sus hospitales y los Campos de prisioneros, y aplicó en la Guerra de África lo aprendido en la Guerra europea.

La experiencia adquirida le convirtió en el primer conocedor de la Ciencia Quirúrgica Militar en nuestro país. Desde 1919 enseñó Cirugía de Guerra en la Academia de Sanidad Militar.

En 1921vuelve la Guerra al Norte de África. Gómez Ulla es encargado de dirigir la asistencia a los heridos en esta Campaña. Se le nombró Cirujano Consultor y Jefe de Equipo Quirúrgico. Apasionado por su deber era para los soldados y oficiales la garantía de no quedar desamparados si caían heridos en el campo de batalla.

En el Hospital de Carabanchel creó una Escuela Quirúrgica que alcanzó merecida fama. En 1929 realizó una gira por diversos hospitales norteamericanos, dedicando especial interés a la Clínica Mayo.

En el Hospital Militar de Carabanchel le sorprendió la Guerra Civil y al trasladarse el Hospital al Hotel Palace con su equipo, siguió tratando allí a cuantos enfermos y heridos ponían bajo su cuidado. Pero al no ocultar su preferencia por el Bando Nacional, fue acusado de Alta Traición y encarce- lado. La Cruz Roja internacional se interesó por él y fue canjeado por un médico vasco y liberado en noviembre de 1938 en el Sur de Francia.

En 1939 ingresó en la Real Academia de Medicina. En 1943 ascendió a Inspector Médico de $1^{\text {a }}$ Clase, equivalente a General de División por lo que fue Jefe de Sanidad del Ejército. En 1942 visitó el Frente Ruso y la Sanidad de la División Azul. Pasó a la Reserva en 1945 y a los pocos días murió víctima de un infarto de miocardio.

Su muerte constituyó una gran manifestación de duelo. Las Hijas de la Caridad le acompañaron en largas filas a ambos lados del féretro transportado en un armón de Artillería. Aunque había dejado escasa obra escrita todos tenían de él la convicción de sus valores humanos. Su dedicación al enfermo traspasaba la dedicación técnica y llegaba al alma y al sufrimiento del enfermo.

Manuel Bastos Ansart llegó por primera vez al Hospital Militar de Carabanchel en 1907 como médico de guardia. Fue voluntario a la Guerra del Norte de África donde fue herido y condecorado. Se interesó por la Cirugía Ortopédica. Dedicó su Tesis doctoral a la «Anatomía y mecánica de la bóveda plantar y sus deformaciones».

Un nuevo destino le llevó otra vez a África, al Peñón de Alhucemas $^{(8)}$. Volvió a Madrid y ganó una plaza de Profesor Auxiliar de Patología Quirúrgica con el número uno.

En 1921 vuelve a la Guerra del Norte de África, y queda en el Hospital-Base de Málaga donde adquirió gran experiencia en las lesiones de guerra y sus secuelas. Desde 1928 a 1932 regentó una Cátedra de Patología Quirúrgica.

Igual que a Gómez Ulla le sorprende la Guerra Civil en el Hospital de Carabanchel y en el Hospital Quirúrgico del Hotel Palace.

Autodenominado neutral optó por la República. Preso después de la Guerra terminó su «Tratado de Traumatología». Pidió ir a la División Azul y no se le permitió. En 1942 fue puesto en libertad.

Manuel Gómez Durán ingresó en 1923 en el Cuerpo de Sanidad Militar, que por aquellos años ya tenía un gran prestigio por las Especialidades Médicas.

En 1929 llegó al Hospital Militar de Carabanchel donde conoció a Gómez Ulla que iba a ser su maestro y modelo. En 1931 estaba en posesión de su Diploma de Cirugía y fue destinado a Tetuán.

En 1936 pasó el Estrecho con el Ejército Nacional, operando sin descanso en el frente, publicó artículos y escribió el esbozo de la que sería su obra más importante. «Cirugía de Guerra» en dos tomos.

Acabada la Guerra Civil formó una escuela de Cirujanos en el Hospital de Carabanchel durante más de 20 años. En 1960, año en el que ingresó en la Real Academia de Medicina,

\footnotetext{
(8) Supone una cierta emoción pensar que en el botiquín de ese Peñón, donde yo pasé unos meses, prestando asistencia sanitaria a una compañía de Regulares y dediqué muchas horas a preparar mi examen para optar al Diploma de Pulmón y Corazón, cincuenta años antes allí hubiera estado nada menos que D. Manuel Bastos Ansart, dedicado al mismo deber asistencial, y que allí concluyera de escribir su opúsculo «Cinemática aplicada a las articulaciones humanas». Estas emociones no son una excepción en la Fuerzas Armadas.
} 


\section{El Hospital Central de la Defensa Gómez Ulla, entre la nostalgia y la esperanza...}

ya en la Reserva, conservaba su puesto, como cirujano consultor. Por esta razón Agustín Esteban Hernández, que es uno de sus últimos discípulos, da testimonio personal de su valía $\mathrm{y}$ enumera sus muchas distinciones y homenajes, y en uno de ellos relata la emoción que sintió cuando presenció en la Academia de Sanidad Militar, el abrazo que se dieron Gómez Durán y Bastos Ansart y no me resisto a poner aquí las palabras con las que el Dr. Esteban relataba esa emoción cuando ambos... «Unidos y separados con la misma vocación, los que fueron figuras preeminentes en los Servicios de Sanidad de las filas nacionales y republicanas se juntaban de nuevo para dar testimonio de la singularidad del Médico en la Guerra».

Esto ocurría en 1960, pero antes de seguir hay que contar otras cosas. Estos tres cirujanos se llevan entre ellos diez años de edad, y los tres, como se ha visto, coincidieron en la Guerra Civil. En los primeros días, de esa Guerra, el Hospital Militar de Carabanchel tuvo su triste protagonismo.

En esos días dos directores del Hospital se suceden terminando sus vidas de forma trágica. Ambos figuran como muertos por la Causa Nacional. El primero es el Coronel Médico Bouthelier que acababa de hacerse cargo del puesto, en comisión de servicio, y fue cesado, sin que se volviera a saber de él. De su sucesor, el Teniente Coronel Federico González Deleito, sí se saben más detalles: Había sido hospitalizado, como enfermo, el General López Ochoa, que había sido enviado por las autoridades de la República para sofocar la Rebelión de Asturias, por lo que un grupo de milicianos trataban de apoderarse de él para matarle. Deleito, mientras el General López Ochoa fuese un enfermo a su cargo, trató de defenderle, pero los milicianos lograron cogerlo, fusilarlo y decapitarlo. Días después fusilaron a Deleito, que ya había sido destituido como director.

Otro hecho, que también pudo acabar en tragedia, sucedió el 4 de agosto de 1936.Las Hijas de la Caridad fueron obligadas a abandonar el Centro, con ropas seglares, las subieron a los camiones que las transportarían al lugar de su fusilamiento, pero uno de los jefes de los milicianos, que reconoció a alguna, que le cuidó como enfermo, cuando hacía el Servicio Militar, gritó: «iAlto compañeros a estas mujeres no se las puede matar porque sólo practican el bien con todos!». Esto hizo que las Hermanas fueran dejadas en libertad en el Puente de Toledo. Allí cada una siguió haciendo, cuando pudo, labores de cari$\operatorname{dad}^{(9)}$.

\footnotetext{
(9) Las Hijas de la Caridad merecen en esta historia otra mención especial: Estas Religiosas que formaron parte del Hospital desde su inauguración, en 1896, cuando llegaron no eran tituladas, se dedicaron a puestos de administración y servicios generales de Intendencia. Las que se dedicaron a servicios sanitarios fueron instruidas por los Jefes de Clínicas. En 1911 el Dr. Gómez Ulla las instruyó en el manejo del material y en la práctica de ayudantes e instrumentistas. Algunas se distinguieron por su dedicación y sacrificio y fueron condecoradas con Cruces Blancas del Mérito Militar. En 1922 se creó la Escuela de Enfermeras San Vicente de Paúl en el Hospital de Carabanchel siguiendo el deseo de SM la Reina Cristina, que se plasmó en esta institución, que no necesitaba más presupuestos ni plantilla que el sentimiento del deber y amor al servicio. Se editó, entonces, un Reglamento y Programa de Enfermeras de San Vicente de Paúl de los Hospitales Militares.

Esta dedicación altruista dio lugar al siguiente hecho que ocurrió en los días anteriores de la Guerra Civil:
}

Este Hospital, que cayó al estallar la Guerra en el bando republicano, luego estuvo en zona de Guerra y sufrió cuantiosos daños. Durante la Guerra la República trasladó su actividad, como ya he precisado, al Hotel Palace de Madrid.

Ahora toca seguir con la Historia del Hospital tras la Guerra Civil. Se inicia una etapa, que coincide con mi infancia, la triste posguerra española, y hay que hablar de recuperación y sucesivas modernizaciones y mejoras del Hospital. Este periodo abarca desde esta fecha hasta el despertar económico de los Planes de Desarrollo, con el pensamiento puesto en un nuevo edificio.

Para esta etapa el libro del Centenario narra la historia de la mano de otro médico militar, especialista en Anatomía Patológica, que también tiene sensibilidad por la Historia de la Sanidad Militar, Patrocinio Moratinos Palomero, detallista de obras y estadísticas que suponen una ardua tarea y una fuente fiable para la investigación histórica. Las características de este artículo me obligan a pasar por estos detalles, citando sus aspectos generales y escogiendo sus puntos históricos y mis propias vivencias.

Acabada la Guerra Civil se efectuaron obras de reconstrucción y de ampliación con la necesidad de expropiaciones para ese fin. Durante cinco años las obras tuvieron una marcha irregular y muchas veces paradas por falta de materiales y complementos.

El abastecimiento de agua, cuando se proyectó el Hospital, era para 500 camas por lo que el abastecimiento estaba asegurado con los 345 metros cúbicos que proporcionaba el Canal de Isabel II. Pero en 1946 las necesidades de agua eran para 1.574 camas, lo que requería 800 metros cúbicos diarios y se estimaba que al final de la obra con 2.600 camas harían falta 1.600 metros cúbicos diarios. A esto habrá que añadir las averías, el tamaño inadecuado de las cañerías, las sequías, etc.

Tras las obras necesarias y la construcción de un depósito subterráneo y otro elevado, se fueron solucionando los problemas que terminaron en 1958.

La energía eléctrica, que también tuvo que soportar la sequía de aquellos años, fue la causa de las restricciones que sufrió España, que recordamos todos los que vivimos en aquella época, en la que a veces preparé mis exámenes de Bachillerato a la luz de un quinqué.

La calefacción se proporcionaba por el sistema de vapor de agua con calderas instaladas en los sótanos de cada edificio,

Siendo Gómez Ulla el director accidental del Hospital lo citó D. Manuel Azaña, presidente de la República, estableciéndose el siguiente diálogo que se cuenta en la biografía escrita por el sobrino del eminente cirujano:

Gómez Ulla, quiero que las monjas dejen Carabanchel pues pretendo sustituirlas por personal civil.

Señor Presidente, esto va a salirle muy caro al ramo de la Guerra. Aparte de eso le diré, excelencia, que las Hijas de la Caridad son insustituibles.

Azaña le replica:

Pero entonces ¿Qué tienen estas mujeres de especial y qué cobran estas monjas, que tan baratas salen al Estado?

Cobran 1,50 pesetas diarias, Señor Presidente.

No lo entiendo ¿Qué pretenden estas Hijas de la Caridad?

Nada Excelencia, simplemente un cachito de Cielo.

Las Hijas de la Caridad no fueron relevadas hasta los hechos referidos, que ocurrieron al principio de la Guerra Civil. 
que se fueron cambiando por el sistema de agua caliente tanto en el Hospital como en la Clínica filial de Vista Alegre de la que hablaré a continuación ${ }^{(10)}$.

Es necesario mencionar la necesidad que hubo en esta época de completar la hospitalización del Hospital de Carabanchel con el que se instaló en el antiguo Colegio de Huérfanos de la Policía Armada, que había en la Finca de Vista Alegre, donde se emplazaron Clínicas Médicas y Quirúrgicas, disponiendo de 1.000 camas, Gabinete de Rayos X, Laboratorio de Análisis Clínicos y Quirófanos. Pero principalmente se utilizó para enfermos tuberculosos, que era la mayor demanda de enfermedad de la época y la mayor causa de mortalidad, seguida de la meningitis de esta u otra etiología. Esta filial se prolongó diez años, devolviéndose a sus antiguos dueños en 1949. Desde 1946 hasta esta fecha sólo quedó la Clínica de Tisiología a cuyo cargo estaba D. Francisco de los Ríos ${ }^{(11)}$, alumno de D. José Valdés Lambea, antes mencionado.

En este año de 1949, se inauguró el Sanatorio Militar Antituberculoso de Guadarrama, que tenía un flujo permanente de enfermos con el Servicio de Tisiología. Hoy es un Geriátrico.

En 1952 se edificó el Pabellón de Maternidad, obra que fue posible por la colaboración del Patronato Militar del Seguro Obligatorio de Enfermedad, y de la que fue paladín defensor D. Alejandro Gómez Durán, que fue su primer Director.

Acontecimiento curioso de esta época de posguerra fue el hallazgo en enero de 1940 del cuadro de Isabel II, pintado por Federico Madrazo, que la Casa Real había regalado a Sanidad Militar y figuraba en la Sala de Juntas. Había desaparecido durante el tiempo en el que he dicho que el Hospital fue zona de guerra y sufrió bombardeos. Sor Benigna Murugarren lo encontró en un almacén cuando buscaba otras cosas para ir preparando el Hospital que debía recibir nuevo enfermos ${ }^{(12)}$.

Un acontecimiento verdaderamente notable fue la Orden de 5 de junio de 1946 por la que los Hospitales Militares de Madrid-Carabanchel y de Tetuán se llamarían desde su publicación Hospital Militar Gómez Ulla.

La era antibiótica había empezado en el Hospital en 1945 con la penicilina, y en 1948 con la estreptomicina. En septiembre de 1954 el Premio Nobel de Medicina Abraham Waksman que había descubierto la estreptomicina, visitó el Hospital Gómez Ulla, con este motivo se dio su nombre a una sala de estudio y lectura.

Otro hecho digno de señalarse en esta época es la Hospitalización a Domicilio, que se adelantó 16 años a la del Hospital de la Santa Cruz y San Pablo de Barcelona, y que se cree

(10) Esta finca del Barrio de Carabanchel, perteneció a la Reina María Cristina. Después la compró el Marqués de Salamanca, y en 1886, dadas las enormes deudas que dejó, sus herederos cedieron la finca al Estado quien la reconvirtió en un gran recinto de establecimientos asistenciales y docentes de titularidad pública.

(11) A D. Francisco de los Ríos no le conocí, fue el jefe de D. José Wilhelmi mi jefe y maestro cuando yo llegué en 1972 a iniciar mi especialidad, al que me referiré más adelante. A la viuda de D. Francisco de los Ríos la conocí cuando iba, durante años, a felicitar, el día de su santo a Sor Concepción, la religiosa que desempeñó, durante tanto tiempo, la atención a los tuberculosos.

(12) Este cuadro pasó a Patrimonio, se instaló en el Museo del Ejército, y se prestó al Hospital para «lucirlo» durante un día, en la antigua sala de Juntas del edificio histórico, cuando se celebró el centenario, oficialmente pionero en este servicio sanitario. En aquella ocasión el Hospital Gómez Ulla tenía una ocupación del 100\% y fue de gran utilidad. Más tarde al concebir un nuevo hospital con Unidades Funcionales de Cuidados Mínimos, Medios e Intensivos, se suplió esta necesidad, como luego apuntaré.

Tras la Guerra Civil se reanudaron los Curso de Especialidades Médicas y sus profesores empiezan a ser nombres cercanos a mi vida como el Comandante Álvarez Pérez de Otorrinolaringología; el Teniente Coronel D. Antonio Vallejo Nájera de Psiquiatría; el Comandante D. Juan Pablo D'Ors de Medicina Interna, hijo del célebre escritor, el Capitán Marcos Clemente, de Anestesia ${ }^{(13)}$; el Comandante Sánchez Galindo, que fue pionero en España de la Cirugía Plástica; el Comandante Francisco de los Ríos de Tisiología que ya nombré al hablar de la Clínica de Vista Alegre.

En el Hospital, al paso que seguían los cursos de Especialidades y surgían especialistas, se estaban creando en los años cincuenta y sesenta nuevos servicios de Especialidades y completándose los existentes.

El Servicio de Neurocirugía aparece en 1955 y el primer neurocirujano es D. Miguel Jiménez Gan. que se había formado con el Profesor Obrador Alcalde. Cuando llegó el Dr. Jiménez Gan introdujo la Angiografía Cerebral, de esta forma el desarrollo de este servicio, se facilitó por los avances de Anestesia y Radiología.

El Servicio de Cirugía Cardiovascular anexo al Servicio de Cardiología, que había empezado a funcionar en 1940, siendo su Jefe D. Pedro Gómez Cuellar, que contaba para el equipo de Cirugía Cardiaca con los capitanes Médicos D. Pedro Muñoz Cardona y D. Justo González Álvarez y con los Tenientes Médicos D. Joaquín Azpeitia y D. Pedro Sanz. En 1958 se puso en marcha un Gabinete experimental de Cirugía Cardiovascular y se hizo un gran análisis crítico sobre el nuevo Servicio y sus posibilidades ${ }^{(14)}$.

(13) Con D. Pascual Marcos Clemente, hablé muchas veces, años después, en animadas tertulias con los médicos de guardia, pues el entonces Teniente Coronel Marcos Clemente tenía su vivienda dentro del recinto del hospital. Era un hombre inteligente y amable, con un gran sentido del humor. Fue General Médico, Jefe de Sanidad de la Primera Región Militar.

(14) Aquí figura D. Justo González Álvarez como adscrito al Servicio de Cirugía Cardiovascular pero merece advertir que Don Justo fue luego un hombre emblemático en el Hospital como Cardiólogo y se comenta en la crónica de cardiología del libro del Centenario que hay tres Figuras en el Hospital que se les conoce más por su nombre (precedido del Don) que por su empleo Militar o apellido. Para mí Don Justo, incluso cuando llegó a General de División fue siempre Don Justo, mi profesor, mi jefe y lo fue sin que esto impidiera que fuese también mi amigo, dado el trato cordial con el que siempre me distinguió. Allí se dice que este exclusivo Don sin nombrar apellidos, lo comparte con Don Juan Pablo D'Ors y con Don Mariano Gómez Ulla. Yo no estuve en el Hospital en tiempos de D'Órs ni de Gómez Ulla, a estos siempre les asocié el apellido, por razones obvias. Pero el Don en el Hospital lo llevó también Don José Wilhelmi, mi primer Jefe de Neumología, al que siempre se le llamaba Don José y cuando no estaba presente se le cambiaba el nombre por San José, dada su gran bondad, cualidad que también le atribuye en la Crónica de Cirugía Torácica el Coronel Esteban. A Don José le enviaban las Conferencias de San Vicente niños de familias pobres con la excusa de que tosían, Don José los auscultaba, les daba un jarabe y les metía en el bolsillo del babero un billete de cien pesetas. Cuenta Sor Concepción que en una ocasión en la que se iba de permiso y dejaba encargado del Servicio a su único colaborador, Ramón Capdevilla, (así era de pobre la plantilla del Hospital), éste le dijo: ¿Y qué hago con los «sanvi- 


\section{El Hospital Central de la Defensa Gómez Ulla, entre la nostalgia y la esperanza...}

El servicio de Odontología había empezado a funcionar en 1923 y ya disponía de un taller de prótesis. Fue notoria la colaboración que mantuvo con el Servicio de Cirugía Plástica desde su instalación en el Hospital de Carabanchel para el tratamiento de mutilados de la Guerra Civil y procedentes de la División Azul. En 1955 se creó la especialidad para el Ejército, que se cursaba en la Escuela de Estomatología.

El Servicio de Hematología y Hemoterapia se creó en 1952 y quedó integrado en el Instituto de Higiene Militar con Secciones en los Hospitales Militares. En 1961 este Servicio Central siguió ubicaciones hasta encontrarse en la calle Donoso Cortés. El Diploma de la Especialidad se creó en 1968, hasta entonces el Servicio estaba a cargo de los diplomados en Análisis Clínicos y Medicina Preventiva.

De esa Especialidad de Análisis Clínicos y Medicina Preventiva se desglosó también el Servicio de Anatomía Patológica. En este Servicio el Dr. Moratinos cita entre otras cosas el hecho de que D. Juan Pablo D'Ors fue el propulsor más insistente de la necesidad de este Servicio y señala al eminente anatomopatólogo Dr. D. Vicente Jabonero Sánchez ${ }^{(15)}$, como fundador del Servicio.

El Servicio de Radiología en los años cuarenta ya contaba con aparatos de Terapia y Radiodiagnóstico. En 1945 tenía ya tres secciones Radioterapia y Curieterapia, Radiodiagnóstico y Electroterapia.

Respecto al Servicio de Obstetricia y Ginecología, es necesario puntualizar que después de la Guerra Civil, los cirujanos generales operaban los procesos ginecológicos. En esa época las mujeres españolas daban a luz en sus domicilios y sólo las distocias eran atendidas en los hospitales. A la creación de la Maternidad que ocurrió en 1954 ya me he referido. Allí existió desde 1956 un Servicio de Pediatría y Puericultura como un anejo de la Maternidad para recién nacidos y prematuros.

Otro Servicio nuevo fue el de Anestesia y Reanimación, que aparece en 1953, pues antes, y sobre todo, antes de la Guerra Civil, la Anestesia y control posterior del paciente la hacían los mismos cirujanos ${ }^{(16)}$. El primer jefe del Servicio de Anestesia fue el Dr. Marcos Clemente, del que ya he hablado, que se formó en Inglaterra y Dinamarca. Su método de trabajo consistía en visitar el día antes al paciente y comprobar su estado físico y emocional, estableciendo una relación de confianza.

Un Servicio emblemático, que se está haciendo en esta época, es el de Medicina Interna del Dr. D’Órs. En su servicio se dan cita invitados ilustres como Orts Llorca, Jiménez Díaz, Ortiz de Landázuri, Teófilo Hernando, Azpitarte,

centinos» Don José?». «Haz lo que quieras -le contestó- estos son billetitos para el cielo» Es bueno recordar aquí a Don Mariano Gómez Ulla cuando le dijo a Azaña lo del «cachito de Cielo» de las monjas.

(15) Al Dr. Jabonero lo conocí al principio de los años setenta en el Instituto Nacional de Silicosis cuando estuve en ese Centro para estudiar Mecánica Ventilatoria en su completísimo Laboratorio de Exploración Funcional Allí el Dr. Jabonero, ya en la Reserva, era un investigador de fama internacional y nos mostraba sus excelentes preparaciones de Patología Pulmonar en sus clases magistrales.

(16) Recuérdese la Anestesia Metamérica de Pagés, que publicó su descubrimiento en la Revista de Sanidad Militar de junio de 1921, donde dice textualmente: «....al practicar una raquianestesia tuve la idea de detener la cánula antes de atravesar la duramadre y me propuse bloquear las raíces fuera del espacio meníngeo».
Casas y entre las figuras universales de la Medicina, el Premio Nobel Profesor Garhard Domagk, y el Fisiólogo Hans Selye que disertó sobre su teoría hipofiso-suprarrenal para explicar el «Síndrome General de Adaptación».

Entre los alumnos del Dr. D'Ors, citaré a Riobó y De La Torre, que fueron directores del Hospital cuando ascendieron a General.

El Servicio de Cirugía Plástica, que fundó y dirigió el Dr. Sánchez-Galindo, tuvo su propia historia singular, detallada por Moratinos y que me contó su hijo Manuel, oftalmólogo del Hospital, cuando publiqué un artículo sobre su padre en el Boletín Informativo de Sanidad Militar.

Este Servicio empezó en San Sebastián en plena Guerra Civil ante la necesidad de disponer de esta cirugía al demandarla las heridas de guerra, como había ocurrido en la Gran Guerra, en la que España no había intervenido. El capitán Sánchez-Galindo, cirujano, formado en la Escuela de Carabanchel, asistió en 1937 a un curso sobre Cirugía Plástica y Reparadora, que dio el Profesor Sheehan, al que siguió después a Estados Unidos, donde continuó su aprendizaje, volviendo al año siguiente a San Sebastián, donde formó el primer Servicio de esa espacialidad que en 1940 se instaló en la Filial de Vista Alegre y en 1942 en el Hospital de Madrid-Carabanchel. Fue el Fundador de la Sociedad Española de Cirugía Plástica, y su primer Presidente, y luego Presidente de Honor. Alumno suyo fue el Dr. D. Juan Quetglas, Jefe del Servicio durante 23 años. El Dr. Sánchez Galindo ascendió a general y fue el primero que se encontró con el anteproyecto del nuevo Hospital.

En los años sesenta se piensa en una estructura del Hospital que responda a Unidades Funcionales, según la gravedad: Cuidados Intensivos, Medios y Mínimos y así se plantearía el Nuevo Hospital para lograr costes más racionales de las estancias hospitalarias. Luego veremos cómo estos conceptos irían adaptándose a los cambios en las Fuerzas Armadas, la Policía Armada (luego Nacional) y Guardia Civil, a la Creación del ISFAS y a la abolición del Servicio Militar obligatorio.

Respecto a las consultas externas, en 1958 se había creado una Policlínica, que se instaló en la planta baja del Pabellón de Entrada al Hospital. En 1961 se pensó en descongestionar al Hospital de estas consultas y crearlas con servicios propios de análisis y radiología. Esto se ubicó en la calle Isaac Peral, donde se construía el nuevo Hospital de Plaza de Madrid, Hospital del Generalísimo. El consultorio se inauguró en 1962, tres años antes que el Hospital que allí se construía. Ya veremos cómo este Hospital irá perdiendo Servicios y en 1988 será una sección del Hospital Gómez Ulla, casi convertido cuando se cerró, en un geriátrico.

Para hablar de la construcción del nuevo Hospital diré que esto no empezó con un incendio como el del Seminario de Nobles, sino con la fractura de un brazo del General Cámpora. Efectivamente D. Juan Cámpora Rodríguez, Doctor Ingeniero de Construcción, General del Cuerpo de Ingenieros de Armamento y Construcción (CIAC), que sufrió esa fractura en enero de 1967, durante su convalecencia, recorrió el Hospital y entonces se propuso construir un hospital nuevo ${ }^{(17)}$.

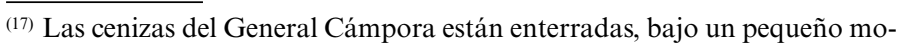
numento, a la entrada del edificio del Hospital. 
El Hospital, proyectado y edificado en el siglo XIX, no sólo no podía mantenerse con reparaciones, sino que ocasionaba una situación incómoda para el personal que trabajaba en él y sobre todo para el enfermo al que le impactaba su mal estado. Ya eran bastantes malos los motivos que llevan a alguien a un hospital, para tener que encontrarse además con una estancia tan penosa por las muchas deficiencias e incomodidades que ofrecía el edificio. El enfermo tenía que hacer un esfuerzo para no incluir, en el aspecto ruinoso del entorno, la actuación profesional del personal sanitario.

Había que volver a una decisión similar a la del siglo XIX. En aquella ocasión se pasó del Seminario de Nobles reformado para hospital, que además de haber sufrido un incendio, ya era obsoleto para su época, a una construcción del Sistema Tollet, que como ya dije, respondía a la modernidad del momento. Ahora se trataba de hacer una obra que atendiese a la nueva modernidad que había ya en Europa y también en España.

De nuevo el relato se me hace pormenorizado. Se trata otra vez de una construcción y hay que contarla para entender la Historia que comienza.

El General Cámpora llamó al Comandante del Cuerpo de Armamento y Construcción D. Emilio Ramos Estaún, con el tiempo General Ramos, para realizar unos proyectos de enfoque previo al que se añadió otro de construcción por fases, pues había que seguir trabajando en el Hospital viejo que iría desapareciendo mientras surgía el nuevo y lo reemplazaba. Historia que muchos vivimos de primera mano.

En abril de 1969 el Ministro del Ejército autorizó la creación de una Comisión Mixta, en la que estaban, con mayor o menor participación activa, todos los Jefes de Servicio.

En los primeros meses de 1971 se canalizó la Financiación del Proyecto hacia el Tercer Plan de Desarrollo, que estaba preparando el Ministro López Rodó, y se aprobó a final de ese año, poniéndose en un acto simbólico la primera piedra, acto al que asistieron, entre otras personalidades, el General Sánchez Galindo y el que había sido ya su sucesor D. Juan Hernández Jiménez.

Iré diciendo las fechas principales de las entregas de esta compleja Construcción Sanitaria con la advertencia de que estas obras que se entregaban no fueron setas que aparecieron en un otoño húmedo, tuvieron un proceso que nos acarreaba, de forma paralela, demolición, escombro, estrechez y provisionalidad. Más adelante añadiré la crónica de una impresión personal.

El año 1973, en el noroeste de lo que sería el Complejo Hospitalario, se empezó a despejar el terreno y se construyó el Tanatorio, y al año siguiente el Pabellón de Cirugía y Medicina Experimental. A los que presenciábamos las obras, en un Hospital viejo y derribándose y nos estrechábamos con sufrida incomodidad, nos maravilló la idea de que si toda esa modernidad era para muertos y animales, cómo serían los lujos que nos aguardaban.

En 1975 se puso en marcha el Pabellón de Cuidados Mínimos, que en el proyecto era principalmente, como antes esbocé, para tropa, pendiente de rehabilitación o tribunales, y se habilitó para atender la hospitalización de los enfermos ingresados en los pabellones que se iban tirando, lo que causó cierta decepción en los primeros enfermos que no esperaban estar en habitaciones compartidas.

En 1979 aumentó la Plantilla del Hospital en más de 1.000 personas y el 30 de octubre de ese año el Órgano Gestor entregó la Torre. Se realizó una inspección minuciosa y el día 22 de noviembre estaba todo preparado. El General Médico D. Anastasio del Campo, que relata esta etapa en el Libro del Centenario, lo describe con estas palabras: «Los enfermos que habían estado ingresados últimamente en las antiguas habitaciones, no salían de su asombro». Ahora en las nuevas funcionaba todo bien, se encendían todas las luces, no se salían las cisternas y no había goteras».

Recuerdo que a los neumólogos nos correspondió la planta octava, de forma provisional y urgente, ya que la antigua Tisiología ${ }^{(18)}$ estaba en la zona norte y urgía su demolición para seguir con las siguientes obras. Entre ese año y principios del siguiente se ocuparían todas las plantas con los enfermos de las otras especialidades médicas y quirúrgicas.

Al final de noviembre inició la actividad en su nuevo lugar el Laboratorio de Análisis Clínicos, y el 5 de diciembre se instaló provisionalmente la Dirección en una sala de Rehabilitación, pues la parte anterior de la Bandeja no estaba terminada y la entrada principal del Hospital precisaba una urbanización adecuada. Pero ya había un hospital moderno que funcionaba y con una Dirección acorde con los tiempos, compuesta por: un Director, un Subdirector, un Jefe de Secretaría Técnica, un Jefe de la División Médico-Administrativa, un Jefe de Consultas Externas, un Administrador y un Jefe de Enfermería.

A principio de 1980 se pusieron en marcha las pruebas funcionales de todos los servicios. Cuando me encontré en

\footnotetext{
(18) Aquí de nuevo surge con la Tisiología y la Cirugía Torácica. algo parecido a lo que ocurrió con Cardiología y Cirugía Cardiovascular y luego ésta separarse en Cirugía cardiaca, y Angiología y Cirugía vascular que ya esbocé antes cuando me dio pie para hablar de D. Justo. cardiólogo por excelencia de esta nueva andadura de la Cardiología, que dada su complejidad exige cinco años de formación en el sistema Mir. La Cirugía Cardiaca precisó en el hospital tras la dedicación ilusionada de sus fundadores, la reorganización que iniciara, D. Pedro Sanz en Cirugía Vascular y D. José Ramón Gutiérrez, que llegó a ser Director de Sanidad del Ejército, y que tras excelentes incorporaciones comenzó también una andadura de prestigio con la formación en la Fundación Jiménez Díaz de D. Juan Miguel Wilhelmi, hijo de mi querido maestro, antes mencionado.

Digo que surgió algo parecido, porque estas separaciones en especialidades, que el adelanto de la Medicina va obligando, se deben a que los viejos especialistas de Pulmón y Corazón, vamos notando, en nuestra historia personal, esta necesidad de renunciar y elegir ante la cantidad de conocimientos y técnicas, que se nos presentan y no podemos abarcar, y así de los antiguos Tisiólogos que en mi enumeración anterior dejé en D. José Wilhelmi, que asumió la Tisiología en su terapéutica médica y quirúrgica (especialmente colapsoterápica) surgió una Cirugía Torácica que propició que Francisco García Marcos polarizara su especialidad de Pulmón y Corazón hacia una Neumología moderna de exploraciones instrumentales y endoscopias, por lo que el Dr. Esteban, que ya he nombrado como iniciador de la Cirugía Torácica en el Hospital tuvo que incorporarle, como destinado, a su Servicio, digo como destinado, porque en realidad se le reconocía como, a su vez, ser el fundador del Servicio de Neumología y que luego dio lugar para que ambos me buscasen un destino similar y me enviaran a Puerta de Hierro, a la Clínica Torácica Victoria Eugenia y al Instituto Nacional de Silicosis para que me formase en Exploración Funcional Respiratoria, y ya en 1976, como dice Martínez Albiach, en su precioso libro Las Escuelas de Neumología y Cirugía Torácica Militares, García Marcos y yo iniciásemos la nueva andadura.
} 


\section{El Hospital Central de la Defensa Gómez Ulla, entre la nostalgia y la esperanza...}

la sala de Pruebas Funcionales de Aparato Respiratorio, que ocupaba un sitio privilegiado, un ángulo de la Bandeja posterior, no daba crédito a lo que veía. Habitaciones amplias, totalmente acristaladas, luminosas y soleadas, con muebles de acero y cristal, me pareció un sueño. Igual les pasó a los compañeros que en las salas vecinas instalaron sus equipos.

La crónica personal de este tiempo, a la que antes me he referido, fue la que escribí en 1996, con motivo del Centenario, y que publiqué en la Revista Medicina Militar, titulado «El Nuevo Hospital. Breve Historia de una mudanza» del que pongo aquí los primeros párrafos.

«Era el final de la década de los setenta. La construcción del nuevo hospital iba invadiendo el lugar de los antiguos pabellones situados en calles sombreadas, marginadas por setos, que sufrían el impacto de la obra y el lógico abandono que suponía su próxima desaparición.

Recuerdo que el Servicio de Aparato Respiratorio, que aún mucha gente llamaba «de Tisiología» y que tenía dos plantas, estaba situado al fondo del recinto en su ángulo norte y por lo tanto era de los primeros en estorbar el avance del edificio de «Cuidados Mínimos», primero que se alzaba como muestra de la inmensa torre del Hospital, que ya desde los cimientos anunciaba su enorme estructura. Ni se podía ni se debía evitar, el pabellón iba a ser destruido, en poco tiempo la piqueta convirtió en escombros el lugar donde habían trabajado, desde principio de siglo, hombres que no compartían ya este mundo con nosotros y que habían aplicado tratamientos que ya eran historia.

Como la tripulación del viejo navío contempla, en dique seco, el desguace de lo que fue su hogar, así asistimos el personal de entonces, el caer de los ladrillos que dejaba al descubierto las habitaciones sin fachada, exponiendo desnudos, al impudor de las miradas, la huella de un cuadro, el grifo de un lavabo o el resto de una percha, testigos mudos de cosas cotidianas, pequeñas o de enorme importancia, para la vida de tantas personas, algunas presentes con mirada perdida y otras muchas desaparecidas.

Los sanitarios habían trasladado ya a los enfermos a otro pabellón más alejado de la obra, era necesario replegarse, se trataba de una mudanza hacia dentro. El viejo mobiliario, amontonado al pie de la escalera, se mostraba como un curioso rastrillo donde alternaban mesas y armarios, algún día barnizados, con bellas escribanías que lucían esculturas de bronce de gusto exquisito, cuya procedencia se ignoraba.

El día antes del derribo se hacia el último traslado en pequeños grupos. Nuestra andadura se parecía a las frecuentes mudanzas que en el siglo pasado se describen en el Madrid galdosiano, donde las familias llevaban en una carreta sus enseres más necesarios en busca de un alquiler más adecuado a su economía. Aquí la improvisada carreta era una de aquellas camillas montadas sobre estructuras con ruedas, y los enseres eran nuestros preciados archivos y el utillaje clínico más delicado, tan necesario para continuar nuestra labor asistencial en el pabellón asignado, que había que compartir con otro servicio, pues la ventaja de tener un día un gran hospital exigía una servidumbre temporal. Desde el nuevo aposento se veía avanzar la inmensa obra, que, como promesa de días mejores, invitaba a soportar las estrecheces del momento.
De vez en cuando, los médicos éramos consultados por los ingenieros que construían el nuevo hospital. No dábamos crédito a los planos que nos enseñaban. En aquella época la mayoría habíamos sido niños de la posguerra, acostumbrados a las apreturas de aquella vida doméstica, y después habíamos vivido la austera economía de los cuarteles y la práctica médica en un hospital antiguo y deteriorado. Era difícil entender que de repente hubiese tanto ofrecimiento. Nuestras posibilidades iban a desbordar los planes imaginados. Teníamos que buscar función para la abundancia de lo ofrecido. Algunas habitaciones los ingenieros las rotulaban con un nombre enigmático «técnicas futuras».

No se ocupó de repente todo lo que sería el nuevo hospital. Había que terminar unas zonas para acabar de derribar lo que iba quedando. Algunos servicios tenían un pie en cada casa. Provisionalmente se habilitaban zonas ya construidas mientras parte de la hospitalización seguía en los viejos pabellones.

Para pasar visita a los enfermos sorteábamos con habilidad, no siempre conseguida, el barrizal que rodeaba a la enorme obra entre placas de hormigón, estructuras metálicas y enormes tuberías de diversos materiales, que la obra engullía vorazmente. Llegábamos a la parte habilitada del edificio pensando en el día en que todo el complejo hospitalario fuera una realidad. El sueño se palpaba ya con la fuerza de lo posible. Eran instalaciones provisionales, pero con la luminosidad de lo nuevo y la blancura de la limpieza.

Un día la gran torre, con la amplia base que se presentaba como una sólida peana, abrió sus puertas ofreciendo sus cómodas habitaciones y sus grandes espacios. Empezamos a descubrir cosas tan sofisticadas que nuestra mente, hecha a la inercia añosa de nuestra economía, se resistía a creer: Sistema de comunicación centralizado, control de llamadas al personal y de servicios realizados, tubos para el transporte de informes, jaulas de Faraday en salas de registros... ¿funcionaría todo eso?; nos mirábamos con una mezcla de incertidumbre y de esperanza...».

El 18 de septiembre de 1980 se inauguraron las instalaciones de Rehabilitación, que no se utilizarían del todo hasta pasados unos meses por cuestiones técnicas y de personal.

En el mismo año se inauguró la Central Telefónica, las cafeterías de familiares y de personal y en la misma planta la Capilla, una obra moderna y elegante, diseñada por el Comandante Ramos.La demolición de la vieja Capilla en 1981, de la que ya he hablado, nos causó dolor a muchos que habíamos rezado y pensado en el silencio de sus bancos.

En este año de 1981se trasladó la Farmacia Hospitalaria con gran alegría de su Jefe D. Luis Gómez Rodríguez ${ }^{(19)}$, que montó el sistema de unidosis y las técnicas de Farmacocinética. También se instaló en este año el Servicio de Urgencias.

En 1981 se hicieron las primeras pruebas de la Central de Esterilización y se instalaron las unidades de Quemados, Trasplantes y los Quirófanos, que estaban en un edificio aparte, donde se encontraba la Unidad de Cuidados Intensivos. Tam-

\footnotetext{
(19) Otro hombre emblemático del Hospital, que estuvo en la ceremonia de instalación y bendición de la primera piedra y ha escrito libros y dado conferencias sobre la vida y las anécdotas del Hospital.
} 
bién en 1981 se instaló la Sección de Hemodinámica y Angiografía y se inició el montaje y pruebas del Ordenador General.

En 1982 comenzó a funcionar la Escuela de Enfermería, dependiente de la Universidad Complutense. El 6 de junio se entregó el Pabellón de Presos y Arrestados. Más adelante, en 1988, al no permitirse tal separación, se instaló allí el EMAT$\mathrm{C}^{(20)}$.

Los días 22, 23 y 25 de junio hubo huelga del personal laboral. Noticia curiosa que añado para apuntillar que ya había llegado la modernidad ${ }^{(21)}$.

En 1984 se trasladaron, del Hospital del Generalísimo, los Servicios de Oncología Radioterapéutica y el de Medicina Nuclear. Se inauguró el Vestíbulo del Hospital y se pudo entrar por la puerta principal. En este vestíbulo se situó el reloj que había estado en el edificio antiguo y estuvo a punto de ser vendido como chatarra. Se colocó en una urna acristalada y su reparación fue obra de Pedro Portellano, el Jefe de Cirugía Vascular y excelente aficionado a la relojería antigua.

En 1985 los Servicios de Radiología y Estomatología pasaron a sus nuevas instalaciones. En este año y en los siguientes se realizaron importantes reuniones de investigación.

Al final de los años ochenta, con motivo de la Guerra entre Irak e Irán, se recibieron enfermos con lesiones en ojos y vías respiratorias achacadas a la acción de gases tóxicos supuestamente disparados por el Ejército Irakí. Yo estaba de guardia en uno de esos ingresos y me tocó tratar a estos civiles, que los iraníes habían enviado a Hospitales Europeos para apoyar sus protestas ante la ONU.

En 1990 el Ministerio de Defensa decidió contratar un sistema informático, común para todos los Hospitales Militares, que se le adjudicó a la Empresa de Estados Unidos SMS. El Plan Malta ${ }^{(22)}$.

${ }^{(20)}$ El Equipo médico avanzado del Ejército de Tierra de la zona Centro, estuvo en este edificio y relazó misiones en el Extranjero y en Territorio Nacional. Estando yo de Director accidental en los últimos meses de este siglo me tocó despedirle cuando se disponía a partir a una de sus misiones y sentí la emoción ajena al comprobar la ilusión de los que partían a realizar la verdadera actividad de sanitarios militares. Su Jefe era el Teniente Coronel Guiote, que como era de prever acabó siendo el General Médico Jefe de la Brisan. En la actualidad la Función Logística del Hospital es la de constituir un cuarto escalón. (Role-4).

(21) Pongo aquí la irónica «llegada de la modernidad» con la convicción de que todo impacto novedoso precisa aprendizaje. En un principio consideré que las reivindicaciones del personal civil iban mal dirigidas. El «patrón» objeto de su actitud estaba en la lejanía del Ministerio al que chillaban, mostrando pancartas. También me chocaba la injusta agresividad de los líderes sindicales en la Reuniones autorizadas. Reuniones a las que los médicos, en las guardias de Jefe de Hospital, teníamos que asistir, en los diversos turnos, con misión exclusivamente testimonial. Cuando ocupé puestos de Dirección entendí que nuestra misión no era la solución de la protesta, sino una apelación a la flexibilidad laboral, que pudiese tener nuestra autoridad. Cuando más adelante, siendo Segente del Hospital, me dijo una sindicalista liberada, que yo, al menos, les comprendía, cosa que antes nunca me hubieran dicho, comprendí que todo necesita aprendizaje.

(22) Para preguntarse sobre este asunto lo mejor es tener una conversación con José Alfonso Delgado. El Proyecto Malta me lo explicó así: Fue el primer intento a nivel nacional, junto con el proyecto HP-HIS del Insalud de desarrollar un SIH (Sistema de Información Hospitalaria) para el conjunto de la Red Hospitalaria de Defensa. Durante 1985 a 1987, tres años costó elaborar el Pliego de Prescripciones Técnicas y sacar el concurso público que se adjudicó a la Empresa Share Medical
En 1991, terminadas las obras del Pabellón de Hematología y Hemoterapia, se trasladó al mismo, el Servicio Central de los tres Ejércitos, que hasta entonces se encontraba en el Hospital Militar del Generalísimo.

Desde el año 1972, que se redactó el anteproyecto, hubieron de trascurrir 20 años para que en 1992, se pudieran determinar finalizadas las obras del Hospital.

Al año siguiente, el 4 de marzo de 1993, SSMM los Reyes D. Juan Carlos y $\mathrm{D}^{\mathrm{a}}$ Sofía, visitaron oficialmente el Hospital, 86 años después de que lo hicieran SSMM los Reyes D. Alfonso XIII y D ${ }^{a}$ Victoria Eugenia.

Era Director el General D. Jesús González Lobo, que luego fue el primer Inspector General de la Defensa tras la creación de los Cuerpos Comunes, que dio lugar a la unidad de la Sanidad Militar de los tres Ejércitos. Esta unificación no afectó, de momento, a la Historia de este Hospital.

En 1996 el Hospital cumplió cien años, siendo su Director el General D. José María de la Torre Fernández, que presidió el comité que celebró los actos del Centenario del 20 al 27 de junio. Los Reyes D. Juan Carlos y D. ${ }^{a}$ Sofía inauguraron estos actos. Tuvo especial relevancia la Recepción que se hizo en el antiguo Pabellón de Dirección, que se conserva como testimonio del pasado. En la antigua Sala de Juntas, presidida por el retrato de Isabel II, que ya comenté, se les mostró a los Reyes la Placa de mármol y bronce, homenaje a los caídos del Cuerpo, inaugurada por SS MM D. Alfonso XIII y D. ${ }^{a}$ Victoria Eugenia en 1910. En la Biblioteca Histórica ${ }^{(23)}$, con libros y Revistas de los siglos XVIII y XIX, los Reyes firmaron en el Libro de Honor. Desde el Pabellón Histórico marcharon a la entrada y descubrieron un monumento conmemorativo del centenario. En el salón de actos se pronunciaron sendos discursos del Inspector General de Sanidad y del Director del Centro, a los que contestó el Rey con un mensaje de aliento y ánimo.

En días sucesivos se celebraron diversos actos. Especialmente emotiva fue la participación del Profesor Laín Entralgo recordando la figura del Doctor Gómez Ulla, cuyo sillón de la Real Academia de Medicina ocupó a la muerte del gran cirujano militar.

El Hospital que iniciaba su nueva andadura tenía función asistencial, pericial, docente, investigadora y logística.

Systems ${ }^{\circledR}$ (SMS) y su sistema Action 2000 comenzando con el Hospital del Aire y siguiendo por los Hospitales Militares de Sevilla, Naval de Cartagena y finalmente el Hospital Militar Gómez Ulla en el que tuvimos que efectuar una difícil migración de sistemas, dado que su Sistema Mapper ${ }^{\circledR}$ dirigido por el Teniente Coronel D. Ricardo Salazar funcionaba bastante bien.

(23) Esta Biblioteca forma parte del Museo actual de Sanidad Militar, que en esta ocasión estaba sólo iniciado con esta presentación histórica. No obstante, ya se estaban recogiendo todos los fondos históricos de los Hospitales Militares que se fueron cerrando. Esta ardua tarea, que consistía en acudir a esos centros y señalar muebles, libros, cuadros y demás objetos de interés, estuvo a cargo de D. Ricardo Muro, primer jefe del Servicio de Inmunología del Hospital, que fue General Director del Hospital, y que dados sus conocimientos en museología, fue fundador y primer Director de este Museo, donde ha realizado varias exposiciones temporales y al que sigue dedicado de forma altruista y eficaz, catalogando objetos, instrumental médico y libros. 


\section{El Hospital Central de la Defensa Gómez Ulla, entre la nostalgia y la esperanza...}

La función asistencial abarcaba al personal militar y sus familias a través del Instituto Social de las Fuerzas Armadas (ISFAS), Creado por la Ley 28/1975 de 27 de junio, sobre Seguridad Social de las Fuerzas Armadas. Plenamente activo desde octubre de 1978, y a cuantos convenios asistenciales irá realizando.

Por su carácter de Hospital Central posee servicios de todas las especialidades, médicas o quirúrgicas existentes en las Fuerzas Armadas y con posibilidad de ampliarse a las que vayan surgiendo. Ya he hablado de las especialidades que iban unidas y se separaron, de Cardiología y Respiratorio y Cirugía Cardiaca y Vascular, también se separarán, en su momento los Servicios de Cirugía Plástica y Maxilofacial etc. Posee Servicios de Infecciosas, de Urgencias, Servicio Central de Documentación Clínica y Archivo de Historias Clínicas, de Asistencia Social, de Bromatología, de Ingeniería y Mantenimiento, de Informática y de Medicina y Cirugía Experimental, pionero en España.

Tiene especial relevancia el Servicio de Telemedicina, pionero a nivel nacional y europeo, que fue durante diez años el de referencia en la OTAN, dando apoyo, tanto a las Misiones Internacionales, como al resto de la Red Hospitalaria Militar.

Cada una de estas especialidades y Servicios tiene su propia historia, pero pormenorizarlas se escapa de los límites de este artículo. Me entretuve algo en el destino que fue tomando mi especialidad original de Pulmón y Corazón porque en esta visión nostálgica priman mis emociones. No obstante, cuando siendo Director José María de la Torre me nombró Jefe de Estudios de Especialidades Médicas y fui asesor de la Escuela Militar de Sanidad, tuve contactos con todos los alumnos y me ocupé de sus rotaciones, y del progreso de sus aprendizajes, me supuso una riqueza enorme el contacto ilusionado con ellos. En esa época también por determinados acuerdos internacionales vinieron a nuestro Hospital compañeros médicos militares de Mauritania e Hispano América a realizar estudios de diversas especialidades. Su aportación cultural y su cortesía fue una forma de comprobar la buena química que existe entre los miembros de la Sanidad de los Ejércitos.

La función pericial, propia de la Institución Militar, se lleva acabo en el Hospital a través de las Juntas Médico-Periciales (mal llamadas antes Tribunales Médicos), Ordinaria, Superior y Psiquiátrica. Las dos últimas se ubicaron en el Pabellón Histórico, que se conservó del viejo Hospital, existiendo en el Hospital Nuevo una Unidad de Reconocimiento Médico-Pericial (URMP) que se ubicó en el Edificio de Cuidados Mínimos.

Respecto a la Función Docente, ya he comentado que desde el principio del siglo XX este Hospital está comprometido con la Formación de las diversas Especialidades, que el avance de la Medicina, va demandando, y cómo ya, en 1898, Comisiones de Médicos y Farmacéuticos Militares salieron al extranjero con el propósito de proporcionar al Ejército todos los recursos que la Medicina poseía para la profilaxis y la curación de las enfermedades.

Por otra parte, al ir narrando la historia del Hospital en sus dos ubicaciones, he ido insistiendo en que este Hospital fue pionero en la Formación de Especialidades Médicas y Quirúrgicas. Apunté que después de la Guerra Civil, en 1941, aparecían ya enumerados los cursos de Formación para casi todas las especialidades que existían. Hoy ya se extienden a casi todas las que ofrece el Sistema MIR ${ }^{(24)}$.

Cuando en 1975 se publicó la Ley de Especialidades Médicas y su Reglamento en 1978 y nació la Formación MIR, Sanidad Militar llevaba setenta años formando especialistas $^{(25)}$.

No obstante, como la norma que se creaba era una formación de calidad y constituía el único camino para conseguir el título de Especialista, Sanidad Militar se adaptó, y en 1980 el Hospital pasó la obligada auditoría para la acreditación docente. Después cada servicio del Hospital debía optar a la acreditación de su especialidad ante el recién creado Consejo Nacional de Especialidades. De esta forma en 1986 el Hospital tenía acreditación docente para 30 especialidades.

Por otra parte, en los años setenta los Hospitales de Madrid, debieron colaborar con la enseñanza pregrado de sus universidades, así los Hospitales Militares Gómez Ulla y del Generalísimo, dieron esta formación para alumnos de Medicina y de Ayudantes Técnicos Sanitarios (ATS). Esta enseñanza se cristalizó en los Convenios de 1974, 1977, 1986 y 1992, que convirtió a este Hospital en Hospital Universitario. que tuvo para los años pre clínicos la opción del Centro de Estudios Universitarios, CEU. y cuando se establecieron, en 1993, las Universidades Privadas, el CEU obtuvo título propio y surgió el Convenio con esta Universidad.

En ese mismo año surgió la Universidad Alfonso $\mathrm{X}$ el sabio (UAX), que conociendo las magníficas instalaciones del Servicio de Rehabilitación del Hospital, consiguió un convenio con el Hospital en aquella época para la formación de Fisioterapia $^{(26)}$.

En el siglo XXI, como luego comentaré, las Fuerzas Armadas tendrán título propio para la Carrera de Medicina.

Muchos otros cursos de formación se han realizado por acuerdos con otras entidades como la Facultad de Farmacia de la Universidad Complutense, la Universidad de Navarra, el Consejo de Seguridad Nuclear...

También se realizaron cursos de Doctorado, pero eso me lleva a ocuparme de la función investigadora del Hospital.

Esta función investigadora ha tenido en este Hospital, una trayectoria discontinua. El Instituto Anatomopatológico, que en su inicio, parecía que iba a ser un proyecto dispuesto para

\footnotetext{
(24) Las Especialidades de Sanidad Militar las hay fundamentales, que son Medicina, Veterinaria, Farmacia, Odontología, Psicología y Enfermería y las otras especialidades a las que esos profesionales podrán optar, como las indicadas que abarca el Sistema MIR, se llamarán complementarias, de las cuales, las habrá críticas para Sanidad Militar, como Cirugía General, Traumatología, Anestesia, Cuidados Intensivos y Medicina Preventiva.

(25) En una reunión para premiar a residentes de la formación MIR, le comenté al Profesor D. José María Segovia de Arana, considerado como uno de los fundadores de esta Formación Posgrado, la antigüedad de las Fuerzas Armadas en esa formación y me contestó que lo ignoraba, y yo creo que era sincero. Una muestra más del estilo castrense a la hora de mostrar sus propios valores y aciertos.

(26) Esta enseñanza comenzó una noche con una llamada telefónica a mi casa del Rector de la Universidad, que enterado de que yo era el Jefe de Estudios del Hospital, me pidió una entrevista para formalizar un convenio para Fisioterapia, cosa que se realizó con suma rapidez al ordenar el General de la Torre una comisión mixta.
} 
este fin, como ya se ha dicho tenía su sitio en los planos del Hospital Militar de Carabanchel, y no se construyó, por lo que este proyecto no llegó a realizarse.

No obstante, la inquietud investigadora siempre estuvo presente. Cuando se comunicó en 1910 el descubrimiento del 606 o Salvarsán, el Hospital que tenía cuatro salas destinadas a enfermedades venéreas, se apresuró a experimentar con este fármaco, estudiar y publicar sus resultados.

Al comentar la actuación de los prestigiosos cirujanos Pagés, Gómez Ulla, Bastos y Gómez Durán, los tres ’primeros coincidentes en la Guerra de Marruecos y los tres últimos en la Guerra Civil, investigaron, no sólo con la novedosa Anestesia Metamérica de Pagés, sino con las técnicas quirúrgicas propias de las Escuelas de Cirugía, que formaron, y que Bastos y Gómez Durán trasladaron a sus publicaciones. Bastos Ansart no sólo aportó su experiencia al observar, en Málaga los heridos en la Guerra de Marruecos, que completó con la experiencia de su Servicio de Cirugía Ortopédica en el Hospital, sino que al recibir también los heridos de la Rebelión de Asturias de 1934, pudo publicar su libro: «Heridas por arma de fuego», que sirvió de base para todos los cirujanos de la Guerra Civil, confirmándose la utilidad del Método Español de la «Cura oclusiva» ${ }^{(27)}$, que luego los doctores Trueta y Jimeno difundieron en la Segunda Guerra Mundial.

La Cirugía experimental, tras la Guerra Civil, se consideró importante como elemento docente en la práctica quirúrgica. Posteriormente en los años 50 y 60, hubo inicios de Cirugía experimental de forma aislada en Cirugía Torácica, Cardiaca y Traumatología.

El Servicio de Cirugía y Medicina Experimental, citado, que se construyó en el nuevo Hospital Gómez Ulla, está perfectamente dotado para animales de experimentación y cuenta con un personal de Veterinaria Militar muy cualificado. En este Servicio se han realizado, y se siguen realizando, muchos trabajos de investigación y tesis doctorales.

Por último, respecto a la Función Logística, ya he dicho que constituye un Role- 4 .

El 9 de marzo de 2001 se acabó el Servicio Militar Obligatorio. Muchas de las ideas que se han tenido en cuenta para la edificación del Hospital no serán ya útiles. El Edificio de Cuidados Mínimos, por ejemplo, se dedicará a otros fines y necesidades.

Es preciso señalar también que la formación de especialistas ha dado lugar a una estrecha relación con la Sanidad Civil. Muchos de nuestros residentes se forman en hospitales del Ministerio de Sanidad o rotan por ellos para perfeccionar determinadas técnicas.

Durante los últimos diez años se ha ido comprobando en toda la Red Hospitalaria Nacional, que la enseñanza de posgrado del Sistema MIR, ha proporcionado una mano de obra utilísima a los hospitales y un aumento evidente del prestigio de los mismos y de la Medicina Española en general. Para la Sanidad Militar esto no es una sorpresa, llevaba muchos años formando especialistas y los alumnos de las especialidades habían contribuido a la misión asistencial e investigadora del Hospital, y como no

(27) Técnica que ya Queraltó inició en la Guerra de la Independencia y asombró a Dominique Jean Larrey, cirujano de Napoleón. podía ser de otra forma nos habíamos incorporado también a esta nueva etapa de la Formación Médica.

Acaba el Primer milenio. En esta época es Director del Hospital mi compañero Pablo Atienza y yo soy el Secretario General Técnico y en los últimos días de diciembre surge algo entre cómico y dramático, la posibilidad de un peligro informático: Los ordenadores no reconocerán la fecha de un año que empiece por «2»y se pueden bloquear ¡Qué peligro!

El 31 de diciembre se dice que el Ministro permanecerá en su despacho. Esa noche, en el Gómez Ulla, cenamos parte del staff de Dirección en animada compañía. Pasadas las doce de la noche nos llegó la noticia de que por el Este, en Australia y Japón, había entrado el Segundo Milenio sin novedad. Podemos dormir tranquilos.

La nota más cómica la puso a la mañana siguiente, Antonio Gracia Sanz, el Teniente Coronel Jefe de la Farmacia del Hospital, que se me presentó muy serio y me dijo: «Tengo la satisfacción de comunicarle, mi coronel, que los medicamentos que ayer no habían caducado hoy siguen sin caducar». Yo, acusando la ironía y el humor, le dije: «Gracias, Antonio, me quitas un peso de encima, comunicaré la buena nueva al General Director». Empieza el Siglo XXI, un nuevo milenio.

En este principio de Siglo, Carabanchel era un Barrio de la ciudad y reivindicaba una atención sanitaria más próxima, sentía este Hospital como algo suyo, lo había visto alzarse en medio de su núcleo urbano, ya no era el viejo Hospital que se fue deteriorando, ahora éste luce con el brillo de lo nuevo, y la lejanía del Hospital Clínico y del 12 de Octubre se le hacía más penosa. Querían el Hospital para el barrio.

La reivindicación empezó un poco antes, cuando era Director el General Velicia, que vivía en el Hospital. Las manifestaciones de los vecinos con pancartas que pedían el Hospital para el barrio, se agrupaban tras la valla de la entrada. El general bajaba de su casa y se mezclaba con la masa y oía los comentarios, «Ahora no hay Mili obligatoria» ... «Un hospital medio vacío»... "Qué pena un hospital tan grande y sin ocupar». Al día siguiente lo comentaba en las reuniones de la Dirección. Pero unos meses después, cuando dirigía el Hospital el General Atienza, y las manifestaciones aumentaron, se organizó una visita de representantes municipales del Barrio y se les mostró el Hospital con las camas operativas reales. Además en aquella época se estaba cerrando el Hospital del Generalísimo y los enfermos que precisaron seguir ingresados de ese Hospital se trasladaron al Hospital Gómez Ulla.

No obstante, la integración en la Sanidad Civil de la Comunidad de Madrid, ocurrió más adelante.

Existió también a principios de siglo el proyecto de un nuevo Hospital Central de la Defensa para sustituir al Hospital Gómez Ulla, en la calle Arturo Soria, donde se encontraba el Hospital del Aire, que se derribaría, y mientras tanto, el Hospital Gómez Ulla debía albergar al personal de ese Hospital, cosa que ocurrió en 2002.

Cuando en 2004 cambió el Gobierno, el nuevo Subsecretario del Ministerio de Defensa, desestimó el proyecto. No se haría un nuevo Hospital. No hubo que hacer una nueva mudanza.

También en 2002 se trasladó al edificio de Cuidados Mínimos del Hospital, el Instituto de Medicina Preventiva, ligado 


\section{El Hospital Central de la Defensa Gómez Ulla, entre la nostalgia y la esperanza...}

al Hospital, como ya apunté, desde su comienzo en 1885 en un torreón del Seminario de Nobles, teniendo su origen en el Instituto Anatomopatológico y luego Laboratorio Histológico e Histoquímico, y después va a cambiarse su nombre por Instituto de Higiene Militar y posteriormente, Instituto de Medicina Preventiva (IMP), que celebró en 2010 sus 125 años de merecido prestigio. Es un organismo independiente pero con una trayectoria paralela al Hospital. Recuérdese ahora que iba a tener su sitio en el Hospital de Carabanchel y al final llegó a él después de más de cien años.

También en este principio de siglo se trasladó la Inspección General de Sanidad (IGESAN) con todas sus dependencias a las plantas cuarta y quinta del edificio destinado a Maternidad del Hospital.

La Revista Medicina Militar, que en 1983 se había ubicado en el Edificio de Cuidados Mínimos, volvió a la Academia de Sanidad Militar en 1996 y de nuevo al Hospital en 2001, siendo yo su Director Ejecutivo.

En 2003 con ocasión del Bicentenario de la Expedición Filantrópica de la Vacuna, dirigida por Balmis se creó una Comisión Nacional a la que pertenecía la IGESAN, que colaboró con un Premio Balmis, con carácter anual, para premiar la acción Sanitaria más relevante del año de una persona o una Institución. El cambio de Gobierno no continuó con esa Comisión y el Premio tuvo una duración similar a la de la Expedición, tres años.(1803-1806, 2003-2006).

Al llegar el General Montero, en un meteórico ascenso, a Inspector General de Sanidad en 2006, se le presentan más de seis años en el cargo por lo que se realizan muchas cosas que es necesario enumerar, agrupadas de forma temática.

Antes debo decir que el General D. Juan Manuel Montero Vázquez era un hombre soltero, que dedicó su vida a su profesión, vivía prácticamente en el Hospital Militar Gómez Ulla, atendiendo a los enfermos de su especialidad de Aparato Digestivo. Cuando ascendió a Inspector siguió la misma trayectoria, incorporando a sus actos la idea religiosa de su espiritualidad, a veces con la exigencia, un tanto doctrinaria, que se imponía a sí mismo.

Creó un plan estratégico de Sanidad Militar en periodos de tres años, algo parecido al Plan META de 1984 del Ministerio de Defensa, con estudios críticos al final de cada periodo para el control de las metas conseguidas.

Era consciente de que la disminución drástica de los efectivos de las Fuerzas Armadas, daba lugar a la reducción de la actividad sanitaria y por tanto de la preparación del personal, por lo que se esforzó en mantener convenios con las Comunidades Autónomas, que tuvieran Hospitales Militares para prestaciones recíprocas, que favorecieran la actividad de los Hospitales.

El 22 de enero de 2010, se firma un acuerdo entre la Universidad de Alcalá y el Ministerio de Defensa para la creación del Instituto de Investigación Biosanitaria de la Defensa, similar a otros de Colaboración entre Hospitales y Facultades de Medicina que tienen por objeto aunar esfuerzos en la misma dirección investigadora, se instalaría en el Gómez Ulla en dependencias cercanas a las que tenía la Universidad San Pablo CEU ${ }^{(28)}$

\footnotetext{
(28) Duró sólo hasta 2013 (Montero ya había fallecido)
}

El 14 de julio de 2010, se firmó el convenio de colaboración entre La Universidad de Alcalá de Henares y el Ministerio de Defensa para la creación de una nueva Unidad Docente de Enfermería que abrirá sus puertas en el Hospital Gómez Ulla durante el curso 2010-2011.

El Hospital Gómez Ulla el 27 de diciembre de 2011 quedó integrado en la Red Sanitaria Pública de la Comunidad de Madrid. El acuerdo se firmó entre la Ministra de Defensa y la Presidenta de la Comunidad, así se cumplía esa anunciada aspiración de los vecinos de Carabanchel.

Otros muchos convenios de índole asistencial, económico y de investigación se firman en esta época: La fabricación de antivirales, con el Ministerio de Sanidad. Aprovechamiento de plasma sanguíneo, con la empresa Grifols. Prácticas de Cirugía Mínima Invasiva, con la Clínica Jesús Usón...

El 20 de enero de 2010 en el Aula Magna de la Facultad de Medicina de la Universidad Autónoma de Madrid se concedió el Premio Nacional de Informática de la Salud 2010 al Servicio de Telemedicina del Hospital Central de la Defensa.

Otro logro de su Gestión, presente en su segundo plan estratégico fue que pudieran los oficiales de Sanidad realizar el Curso de Estado Mayor.

Durante su etapa de Inspector se instaló el nuevo Plan de Modernización de los Sistemas Informáticos de Sanidad de Defensa (SISANDEF), que contó con su apoyo y animación $^{(29)}$.

En 2009 fue un Servicio del Hospital la Psicología Clínica ${ }^{(30)}$ que luego en 2016 se convertiría en una Sección dentro del Servicio de Psiquiatría y Salud Mental.

(29) De nuevo acudo a José Alfonso Delgado: En 2008 se instaló el nuevo Sistema de Información Sanitaria de Defensa (SISANDEF) conocido como Proyecto Balmis. Desde entonces el Sistema mejora su carácter tecnológico con la incorporación del Proyecto de Imagen Digital Salvany.

No me extrañó nada que además de las mejoras técnicas, que sin duda ofrecía el nuevo sistema, el General Montero lo incorporase a su mente autoritaria para estimular y exigir ese esfuerzo, que las nuevas tecnologías llevan consigo, pues el ordenador y su potencia no es lo esencial sino la colaboración del personal que lo maneja.

Por otro lado supongo que los nombres que a este proyecto se están dando de utilizar para ello a los protagonistas de la Expedición Filantrópica de la Vacuna, le van pareciendo muy bien. Su orgullo patriótico le predispone a propagar los valores olvidados de lo español por lo que era su costumbre, cuando firmaba un escrito suyo de opinión, poner en el año de la fecha una efeméride mundial de tinte español. Además su espiritualidad, a la que antes me he referido, le hacía tener una cierta debilidad con Salvany, que en la Expedición de la Vacuna, tuvo un comportamiento casi misionero, dejándose la vida por los difíciles caminos de América del Sur, mientras Balmis, al que él empezó a llamar el innombrable, por su duro corazón, que buscaba exclusivamente la eficacia última de su trabajo, desoía las peticiones de ayuda que Salvany, dada su debilidad física, cursaba para España. Esto hacía que en las largas charlas, que propiciaba nuestra amistad y la cercanía de mi vivienda al Hospital, yo le dijera, con cierto humor, que no odiase a Balmis, que sin duda se comportaba igual que él, no haciendo dejación de su autoridad, y que además si él hubiese sido el Director de aquella hazaña hubiera tenido especial cuidado para no llevar como subdirector a un hombre de naturaleza enfermiza. Pude advertir que este planteamiento no le desagradaba y por lo tanto este binomio Balmis-Salvany le pareciese un nombre apropiado para los sistemas informáticos de Sanidad de Defensa.

(30) En las Fuerzas Armadas la Psicología es especialidad fundamental por eso la Psicología Clínica adquirió servicio propio, aunque luego fuera concebida como integrada en la Salud Mental. 
También favoreció el General Montero que el Servicio de Medicina y Cirugía Experimental pasara en 2009 a depender del Centro Militar de Veterinaria (CEMILVET) ante un peligro circunstancial, que hubo durante su mandato, de que fuese eliminado del Hospital Gómez Ulla ${ }^{(31)}$.

Estrechó relaciones con la Real Academia de Medicina de Madrid, realizándose en 2010, un ciclo de conferencias sobre la Sanidad Militar.

Respecto a la Función Logística Operativa se encontró con la más difícil y penosa tarea de su mandato. Las misiones internacionales reclamaban sanitarios para desempeñar misiones de asistencia en zona de conflicto. La escasez de personal y su preparación eran retos difíciles de superar. Creó las listas únicas y procuró dotar de medios de formación acelerada a ese personal. La utilización de reservistas y la modificación de las células de estabilización fueron otras de sus luchas para este cometido. De igual forma se preocupó por la atención a familiares de los sanitarios destacados en las diferentes misiones.

$\mathrm{Su}$ lucha al afrontar los inconvenientes fue enorme, prueba de ello fue su interés por abordar el problema con soluciones a largo plazo, que él ya no vería. Me refiero a la creación del Centro Universitario de la Defensa (CUD). que vendría a solucionar los problemas logísticos. Se trataba de un Convenio entre la Universidad de Alcalá y el Ministerio de Defensa, que ofrecía estudiar Medicina tras la selectividad, incorporándose como cadetes a la Escuela Militar de Sanidad, estudiando el contenido de la carrera en la Universidad de Alcalá y en el Hospital Gómez Ulla, con el compromiso de permanecer, al menos doce años en el Cuerpo Militar de Sanidad, pudiendo cursar una especialidad de las que se ofrecieran según las necesidades de dicho Cuerpo.

Respecto a la Revista de Sanidad, que, como he dicho, estaba de nuevo en el Hospital Gómez Ulla, el General Montero presidió todas las reuniones del Comité de Redacción. En 2009, bajo su dirección, se cambió el nombre de la Revista, llamándose de nuevo «Sanidad Militar» en vez de «Medicina Militar», para que se sintieran más representadas todas las Especialidades Fundamentales de Sanidad Militar. Ese año consiguió del Ministerio de Defensa la creación de un premio de Investigación que llevó el nombre de Fidel Pagés, dotado con $9.000 €$ (6.000 de premio y 3.000 de accésit). Se concedió en nueve ocasiones, se hizo internacional en 2012 y, tras resolverse problemas administrativos, este año 2021, se convocó por décima vez. En 2010 se indexó la Revista en la «Scientific Electronic Library Online»(Scielo). En 2011 se inauguró, en la planta baja de Cuidados Mínimos, la nueva sede de la Revista y se indexó en Latindex.

La muerte del General Montero el 21 de mayo de 2012, cuando asistía en la Capital Israelí a una Reunión de Jefes de Sanidad de la Alianza Atlántica, le impidió disfrutar de sus últimos objetivos conseguidos.

A los pocos días de su muerte, en dos acontecimientos sociales se sintió su presencia: El 4 de junio hubo, de nuevo, un

\footnotetext{
(31) Para esta Gestión contó con el asesoramiento de su amigo y colaborador, el General Veterinario D. Luis Moreno Fernández-Caparrós. Volvió posteriormente a depender del Hospital Gómez Ulla, cuando cesaron las dificultades administrativas.
}

acto en la Real Academia de Medicina, que también protagoniza la Presidenta de la Comunidad de Madrid, que al conocer que a un médico militar español, Fidel Pagés, se le debe la anestesia epidural, quiso rendirle un homenaje, por lo que se considera, que la Real Academia de Medicina, con presencia de la Sanidad Militar, constituye el marco adecuado. A esta Reunión asistió el General Muro, no sólo por ser el general más antiguo de la Inspección General de Sanidad, sino porque como fundador y director del Museo de Sanidad Militar, era un estudioso de la vida de Pagés, y tuvo la deferencia de encontrar las palabras, que para este fin tenía escritas el General Montero y leerlas como homenaje al amigo ausente.

El otro acto social fue en el Centro de Promoción de la Policía Nacional, donde se descubrió una placa en memoria y reconocimiento por haber estado en ese Centro la filial de Vista Alegre del Hospital Militar de Madrid Carabanchel. El General D. Luis Hernández Ferrero, sucesor del General Montero, como Inspector General de Sanidad, le recordó como el promotor de este acto.

En 2013 se impartió en las instalaciones del Servicio de Medicina Subacuática e Hiperbárica el primer curso de formación y manejo de la Cámara Hiperbárica. El Hospital tenía así un nuevo servicio que ha seguido impartiendo Másteres de Medicina Subacuática e Hiperbárica ${ }^{(32)}$.

El 11 de marzo de 2014 las hijas del Doctor Bastos Ansart, visitan el Museo de Sanidad Militar. Hay una Exposición Temporal en memoria de su padre, donde puede verse el busto del mismo realizado en madera entre los años 1932 y 1934 obra del célebre escultor Emiliano Barral, que habían donado al Museo(33).

E1 27 de junio de 2014, día de Nuestra Señora del Perpetuo Socorro, el Inspector General de Sanidad, D. Luis Hernández Ferrero, próximo ya su pase a la Reserva, dedica el día festivo del Cuerpo a las Hijas de la Caridad ${ }^{(34)}$. Con esta ocasión se muestra en el Museo de Sanidad Militar una exposición temporal dedicada a ellas ${ }^{(35)}$. Las Hijas de la Caridad dejaron definitivamente el Hospital en 2017.Y el 27 de enero de 2018 se les rindió un homenaje, presidido por el Inspector General de Sanidad D. Santiago Coca, que pronunció una alocución destacando el cariñoso y vigilante trato a los enfermos y la

(32) Esta disciplina es Especialidad exclusivamente Militar pero con estos cursos la Universidad de Alcalá concede un Máster, que permite su manejo a los médicos civiles.

(33) Este escultor hizo también otro busto en piedra de Bastos Ansart, que se conserva en el Ilustre Colegio Oficial de Médicos de Madrid. En esta exposición puede verse también el magnífico retrato del Doctor Bastos realizado por el notable dibujante militar Javier Cabanas.

(34) El General en su discurso, tras recordar que estas religiosas están presentes en este Hospital desde su creación en 1896, dijo entre otras cosas: «...Nosotros somos una familia sanitaria sometida a una obediencia semejante a la conventual por nuestra condición de militares, y la visión de estas mujeres consagradas, es un ejemplo permanente... En una palabra somos dos ejércitos disciplinados en continua convivencia y que a nuestra manera disimulamos ese orden jerárquico porque la Medicina nos enseña que aquel que hoy se siente sabio con su verdad, mañana será llamado a la humildad por errores inevitables».

(35) En esa exposición destaca un dibujo a grafito de Javier Cabanas con una exhortación de San Vicente de Paúl: «Por monasterio tendréis las salas de los enfermos. Por clausura las calles de la ciudad. Por rejas el temor de Dios. Y por velo la santa modestia». 


\section{El Hospital Central de la Defensa Gómez Ulla, entre la nostalgia y la esperanza...}

profesionalidad de su labor, que dejan un profundo agradecimiento en la memoria de la Sanidad Militar. Numerosas religiosas acudieron a este homenaje acompañadas por la Visitadora Provincial María Eugenia González.

Tras el brote de ébola en África Occidental en 2014, el Gobierno Español creó un Comité de crisis específico para el ébola ${ }^{(36)}$, y el 8 de noviembre de ese año, se publicó un Real Decreto por el que se llevaría a cabo la remodelación de la planta 22 del Hospital Central Gómez Ulla para crear una «Unidad de Aislamiento Hospitalario de Alto Nivel» (UAAN), cuya inauguración tuvo lugar el 13 de octubre de 2015, presidida por la Vicepresidenta del Gobierno, acompañada por los Ministros de Defensa y Sanidad, siendo recibidos por el Inspector General de Sanidad, que se refirió en su presentación a que esta Unidad responde a una necesidad puesta de manifiesto en diciembre de 2013, cuando se creó en el Hospital la Unidad Funcional NBQR (actual Unidad NRBQ-infecciosas) para dar respuesta a las necesidades operativas de nuestras Fuerzas Armadas con tropas desplegadas por todo el mundo y sometidas, entre otros, a riesgos biológicos por patógenos desconocidos en nuestro medio. Agradeció el apoyo de la Comunidad Autónoma de Madrid para esta remodelación y puesta en funcionamiento con vistas a una utilización conjunta.

El 18 de febrero de 2016, SM el Rey Felipe VI visitó esta Unidad de Aislamiento acompañado del Ministro de Defensa y la Subsecretaria de ese Departamento y fueron recibidos por el Inspector General de Sanidad, el Director del Hospital y el Jefe de la NRBQ y de la Unidad de Aislamiento.

El 28 de septiembre de 2016 se probó el nuevo proyecto SISANDEF-Cendala ${ }^{(37)}$, cuyo objetivo final es poder registrar toda la actividad Sanitaria Militar en un sistema común para las Fuerzas Armadas, tanto en Territorio Nacional como en Zona de Operaciones. Habiéndose planteado crear los siguientes módulos: Gestión de Vacunación, Reconocimientos Médicos, Datos e Identificación Sanitaria, Actividad Asistencial, Salud Pública y Telemedicina/Teleasistencia.

El día 2 de noviembre de 2018 la Ministra de Defensa, acompañada por el Subsecretario de ese Ministerio, inauguró la apliación de la UAAN y también visitó el Servicio de Telemedicina con los profesionales del Hospital.

El 10 de julio de 2018, en el Paraninfo de la Universidad de Alcalá, 22 alumnos del CUD se graduaron en Medicina, tras seis años de carrera, que había comenzado, como se señaló, en 2012. El 16 de julio se celebró en la Academia Central de la Defensa el acto de clausura del curso de la Formación de los Cuerpos Comunes, y el 18 de julio SM el Rey Felipe VI, presidió la entrega de Reales Despachos de Tenientes en la Academia Central de la Defensa.

El 31 de enero de 2020, llegaron a la base aérea de Torrejón, los españoles repatriados de la ciudad China de Wuhan. Estaban asintomáticos y con test negativos, tanto a su salida como a su llegada a España. Fueron trasladados al Hospital

\footnotetext{
(36) Sanidad Militar colaboró con la aeroevacuación de enfermos en traslados mecanizados en cámaras de aislamiento individual aséptico y la adquisición de material sanitario de aislamiento, protección y desinfección.

(37) De nuevo la Expedición Filantrópica de la Vacuna, presta el nombre de una mujer caritativa.
}

Gómez Ulla donde pasaron una cuarentena de 14 días en la planta 17 del hospital, que no es una sala de aislamiento, pues no se trataba de personas enfermas, siendo observadas por personal sanitario experto en esta clase de situaciones. Los evacuados manifestaron estar cansados después de 30 horas de viaje, pero contentos y agradecidos.

La pandemia de la COVID-19 ha sido un reto para toda la Sanidad Española en general y por lo tanto para la Sanidad Militar, que activó, desde el 15 de marzo, la Operación Balmis, que abarca un amplio campo de actividades de la Sanidad del Ejército de Tierra, Aire y de la Armada, así como de la Unidad Militar de Emergencias. La actividad asistencial de este Hospital, se reforzó con la presencia de especialistas que ocupaban otros destinos.. La acción coordinada de toda la Sanidad Militar está detallada en la Editorial de la Revista Sanidad Militar (Sanid.mil.2020;76(2).54-55) del Inspector General de Sanidad, General de División Médico D. Antonio Ramón Conde Ortiz. En este mismo número de la Revista y en el siguiente, se publicaron una serie de artículos sobre la actividad de Sanidad Militar en relación con la Pandemia.

Cuando el calendario me acerca a las fechas de 2021 el relato de este artículo, que precisaba los 125 años de este Hospital, ha llegado a su fin. No obstante, debo recordar lo que expuse al principio sobre la nueva denominación del Hospital Central de la Defensa Gómez Ulla, que me ha inspirado una visión nostálgica.

La Orden Ministerial, que ha dado al Hospital su nuevo nombre, expone en acertado preámbulo, un resumen de los motivos que lo inspiran: Nombra aquellos puntos en los que un Hospital Militar parece que se sale de su labor exclusiva con el nuevo nombre que incluye, la vida y la esperanza. Esos puntos son circunstancias que emocionan y que yo he querido ir desgranando en este artículo al hilo de mis emociones.

Con profundo agradecimiento recibí en este Hospital, de forma desinteresada, la formación de especialista, una formación que se había establecido setenta años antes de que la educación académica oficial lo realizara, aunque la atención de tal Servicio Sanitario se demandase.

Esta formación la recibí yo, y muchos de mis compañeros, de profesores, autodidactas, que no acumularon con ello más fortuna que la escuela creada de sucesivos profesores.

Con placer recibí en el Hospital a mis vecinos de Carabanchel cuando se maravillaron de $m i$ Hospital y lo recibieron como algo bueno para el Barrio.

También con emoción compartí mi saber de Neumólogo con los compañeros Médicos Militares de Hispanoamérica o de Mauritania, que me traían las costumbres y valores de sus respectivas comunidades.

Con un sentimiento de humanidad atendí a las víctimas de la Guerra Irak-Iraní.

Con orgullo he contemplado, ya desde la terraza de mi domicilio, y en mi situación de retirado, las grúas que cambiaban el skyline de mi horizonte norte, al realizar las obras de la Unidad de Aislamiento de Alto Nivel en la Torre del Hospital, que le diferencia de otros de mayor entidad, confirmando la esperanza, en parte cumplida, de adelantarse a las crisis sanitarias. 


\section{Herrera-de-la-Rosa A.}

Por todo ello, el hecho de que el Hospital sea Militar no ha debido ser una fútil coincidencia, pues en primer lugar la Sanidad Militar está formada por personas con una doble vocación de servicio y espíritu de disciplina, y en segundo lugar porque este Hospital Central de la Defensa es el único Hospital, con avanzada tecnología, que depende directamente del Estado, y por tanto dispuesto a cumplir las órdenes, que para el bien general, ese Estado disponga.
Estas emociones mías enlazan muy bien con mi nostalgia porque, como dice Ortega, «Hay en el hombre muchas emociones dobles...la nostalgia, por ejemplo, con ella echamos de menos algo que un día gozamos...pero el gesto de desolación, con que añoramos el tiempo feliz, concluye en un gesto de placer...y es que la nostalgia es hacia dentro dolor y hacia fuera placer».

Por esto este artículo lleva emociones placenteras, que procuro siempre disfrutar, y compartir hoy con los lectores, en estos años míos de avanzada edad. 